Research Article

\title{
A Preferable Airborne Integrated Navigation Method Based on INS and GPS
}

\author{
Xiaoyue Zhang (D) and Kaiwen Ning \\ School of Instrumentation Science and Optoelectronics Engineering, Beihang University, Beijing 100191, China \\ Correspondence should be addressed to Xiaoyue Zhang; zhangxiaoyue@buaa.edu.cn
}

Received 24 August 2017; Revised 10 January 2018; Accepted 6 February 2018; Published 19 June 2018

Academic Editor: Eduard Llobet

Copyright (c) 2018 Xiaoyue Zhang and Kaiwen Ning. This is an open access article distributed under the Creative Commons Attribution License, which permits unrestricted use, distribution, and reproduction in any medium, provided the original work is properly cited.

\begin{abstract}
An integrated navigation method based on INS and GPS was proposed for airborne navigation. The influence of scale factor error and misalignment error of gyroscope and accelerometer on navigation accuracy was analyzed. Compared with traditional INS/GPS integrated navigation method, scale factor error and misalignment error were added to the state model of the integrated navigation system. The observability of scale factor error and misalignment error was analyzed combined with typical airborne movement. Then the integrated system was optimized, and the new navigation model of the integrated system was obtained. The optimized INS/GPS integrated model was validated by numerical simulation and turntable test. Comparing the proposed model with traditional integrated model (integrated system error states do not include scale factor error and misalignment error), the results showed that the proposed integrated navigation method can improve the accuracy from $8 \%$ to $28 \%$ of the east, north, and upward positions.
\end{abstract}

\section{Introduction}

Inertial navigation system (INS) is an autonomous navigation system that does not depend on any external information $[1,2]$. However, the characteristics of the location error accumulate with time, making it difficult to work independently for a long time. Global Positioning System (GPS) can measure three-dimensional position and velocity accurately, but the disadvantage is susceptible to interference and control [3-5]. Therefore, INS and GPS have complementary characteristics. Since the 1990s, INS/GPS integrated navigation system has been a great success at home and abroad, and it has developed into a specialized technology $[6,7]$.

INS/GPS integrated navigation system works as follows: when GPS signal is good, the system selects the integrated navigation mode. The precision of integrated navigation basically depends on GPS precision, and the inertial measurement unit (IMU) errors can be estimated and compensated online. When GPS signal is disturbed or shielded, the system automatically shifts into inertial navigation mode. At this point, navigation accuracy basically depends on the precision of IMU [8]. Therefore, the estimation accuracy of IMU errors in integrated navigation can affect the accuracy of the subsequent inertial navigation $[9,10]$. In airborne INS/GPS integrated navigation system, however, the errors of IMU only consider the bias of gyroscope and accelerometer without considering scale factor and misalignment at present. A method of the dynamic parameter identification of the scale factor error and misalignment error was designed based on Kalman filter. The observability of the scale factor error and misalignment error with different maneuvers was analyzed in [11]. Zhou et al. described the error dynamic system equation and observation equation of inertial navigation system and the singular value of the system states of online calibration [12]. Therefore, a more advanced method can be designed to make the IMU errors (including bias, scale factor, and misalignment) be more accurate in estimation and compensation in the integrated navigation process. When entering the inertial navigation mode, it can get higher navigation accuracy.

For the application of airborne navigation, this paper analyzes the influence of scale factor error and misalignment error on the accuracy of integrated navigation. Based on the 
analysis, the scale factor error and the misalignment error are added to the error model of the integrated navigation system. Then the observability of the scale factor error and misalignment error is analyzed combined with the typical airborne movement. According to the observability analysis results, the integrated system is optimized and the new error model of the integrated navigation system is obtained. Finally, the optimized INS/GPS integrated model proposed in this paper is validated by numerical simulation and turntable test, and then the proposed model is compared with the traditional integrated model.

\section{Error Analysis of Airborne Inertial Measurement Unit}

The errors of inertial measurement unit mainly include bias, scale factor error and misalignment error. The error model of INS and IMU is given in the following passage, and the influence of IMU errors on the navigation accuracy is analyzed combined typical airborne movement.

\subsection{Error Model of Inertial Navigation System.}

$$
\begin{aligned}
\delta \dot{\lambda} & =\frac{v_{E}^{n} \tan L \sec L}{R_{N}+h} \delta L-\frac{v_{E}^{n} \sec L}{\left(R_{N}+h\right)^{2}} \delta h+\frac{\sec L}{R_{N}+h} \delta v_{E}^{n}, \\
\delta \dot{L} & =-\frac{v_{N}^{n}}{\left(R_{M}+h\right)^{2}} \delta h+\frac{1}{R_{M}+h} \delta v_{N}^{n}, \\
\delta \dot{h} & =\delta v_{U}^{n} \\
\delta \dot{\mathbf{v}}^{n} & =\mathbf{f}^{n} \times \boldsymbol{\varphi}-\left(2 \boldsymbol{\omega}_{i e}^{n}+\boldsymbol{\omega}_{e n}^{n}\right) \times \delta \mathbf{v}^{n}+\mathbf{v}^{n} \times\left(2 \delta \boldsymbol{\omega}_{i e}^{n}+\delta \boldsymbol{\omega}_{e n}^{n}\right)+\delta \mathbf{f}^{n}, \\
\dot{\boldsymbol{\varphi}} & =-\left(\boldsymbol{\omega}_{i e}^{n}+\boldsymbol{\omega}_{e n}^{n}\right) \times \boldsymbol{\varphi}+\delta \boldsymbol{\omega}_{i e}^{n}+\delta \boldsymbol{\omega}_{e n}^{n}-\boldsymbol{\varepsilon}^{n},
\end{aligned}
$$

where $\delta \lambda, \delta L$, and $\delta h$ represent the longitude error, the latitude error, and the altitude error, respectively, and $R_{M}$ and $R_{N}$ are the curvature radius of the meridian and prime vertical. $\delta \mathbf{v}^{n}$ and $\varphi$ represent velocity error and attitude error, respectively, and $\delta \mathbf{f}^{n}$ represents the accelerometer measurement error, which contains accelerometer bias, scale factor error, and misalignment error. $\boldsymbol{\varepsilon}^{n}$ represents the gyroscope measurement error, which contains gyroscope bias, scale factor error, and misalignment error.

\subsection{Error Model of Inertial Measurement Unit.}

$$
\left[\begin{array}{c}
\varepsilon_{x}^{b} \\
\varepsilon_{y}^{b} \\
\varepsilon_{z}^{b}
\end{array}\right]=\left[\begin{array}{l}
\mathrm{gB}_{x} \\
\mathrm{gB}_{y} \\
\mathrm{gB}_{z}
\end{array}\right]+\left[\begin{array}{ccc}
\mathrm{gSF}_{x} & \mathrm{gMA}_{x y} & \mathrm{gMA}_{x z} \\
\mathrm{gMA}_{y x} & \mathrm{gSF}_{y} & \mathrm{gMA}_{y z} \\
\mathrm{gMA}_{z x} & \mathrm{gMA}_{z y} & \mathrm{gSF}_{z}
\end{array}\right]\left[\begin{array}{c}
\omega_{i b x}^{b} \\
\omega_{i b y}^{b} \\
\omega_{i b z}^{b}
\end{array}\right],
$$

where $\mathrm{gSF}_{x}, \mathrm{gSF}_{y}$, and $\mathrm{gSF}_{z}$ are the gyroscope scale factor errors of the $x$-axis, $y$-axis, and $z$-axis. $\mathrm{gMA}_{x y}, \mathrm{gMA}_{x z}$, $\mathrm{gMA}_{y x}, \mathrm{gMA}_{y z}, \mathrm{gMA}_{z x}$, and $\mathrm{gMA}_{z y}$ are the gyroscope misalignment errors. $\mathrm{gB}_{x}, \mathrm{gB}_{y}$, and $\mathrm{gB}_{z}$ are the gyroscope biases. $\omega_{i b x}^{b}, \omega_{i b y}^{b}$, and $\omega_{i b z}^{b}$ are the gyroscope ideal outputs.

$$
\left[\begin{array}{c}
\delta f_{x}^{b} \\
\delta f_{y}^{b} \\
\delta f_{z}^{b}
\end{array}\right]=\left[\begin{array}{c}
\mathrm{aB}_{x} \\
\mathrm{aB}_{y} \\
\mathrm{aB}_{z}
\end{array}\right]+\left[\begin{array}{ccc}
\mathrm{aSF}_{x} & \mathrm{aMA}_{x y} & \mathrm{aMA}_{x z} \\
\mathrm{aMA}_{y x} & \mathrm{aSF}_{y} & \mathrm{aMA}_{y z} \\
\mathrm{aMA}_{z x} & \mathrm{aMA}_{z y} & \mathrm{aSF}_{z}
\end{array}\right]\left[\begin{array}{c}
f_{x}^{b} \\
f_{y}^{b} \\
f_{z}^{b}
\end{array}\right],
$$

where $\mathrm{aSF}_{x}, \mathrm{aSF}_{y}$, and $\mathrm{aSF}_{z}$ are the accelerometer scale factor errors of the $x$-axis, $y$-axis, and $z$-axis. $\mathrm{aMA}_{x y}$, $\mathrm{aMA}_{x z}, \mathrm{aMA}_{y x}, \mathrm{aMA}_{y z}, \mathrm{aMA}_{z x}$, and $\mathrm{aMA}_{z y}$ are the accelerometer misalignment errors. $\mathrm{aB}_{x}, \mathrm{aB}_{y}$, and $\mathrm{aB}_{z}$ are the accelerometer biases. $f_{i x}^{b}, f_{y}^{b}$, and $f_{z}^{b}$ are the accelerometer ideal outputs [13].

2.3. Analysis of the Influence of IMU Errors on Navigation Accuracy. In order to facilitate quantitative analysis, combined with the actual low-precision inertial navigation systems commonly used in airborne navigation, the error parameters of the IMU are set as follows:

$$
\begin{aligned}
\mathrm{gB} & =1^{\circ} / \mathrm{h}, \\
\mathrm{gSF}_{x} & =\mathrm{gSF}_{y}=\mathrm{gSF}_{z}=300 \mathrm{ppm}, \\
\mathrm{gMA}_{x y} & =\mathrm{gMA}_{x z}=\mathrm{gMA}_{y x}=\mathrm{gMA}_{y z}=\mathrm{gMA}_{z x}=\mathrm{gMA}_{z y}=40^{\prime \prime}, \\
\mathrm{aB} & =500 \mu \mathrm{g}, \\
\mathrm{aSF}_{x} & =\mathrm{aSF}_{y}=\mathrm{aSF}_{z}=300 \mathrm{ppm}, \\
\mathrm{aMA}_{x y} & =\mathrm{aMA}_{x z}=\mathrm{aMA}_{y x}=\mathrm{aMA}_{y z}=\mathrm{aMA}_{z x}=\mathrm{aMA}_{z y}=40^{\prime \prime} .
\end{aligned}
$$

2.3.1. Analysis of Attitude Error. In order to more clearly and easily analyze the influence of gyroscope scale factor error and misalignment error on attitude error, we temporarily do not consider other terms. The attitude error equation can be simplified as

$$
\begin{aligned}
\dot{\boldsymbol{\varphi}} & =-\mathbf{C}_{b}^{n}\left(\left[\begin{array}{ccc}
\mathrm{gSF}_{x} & \mathrm{gMA}_{x y} & \mathrm{gMA}_{x z} \\
\mathrm{gMA}_{y x} & \mathrm{gSF}_{y} & \mathrm{gMA}_{y z} \\
\mathrm{gMA}_{z x} & \mathrm{gMA}_{z y} & \mathrm{gSF}_{z}
\end{array}\right]\left[\begin{array}{c}
\omega_{i b x}^{b} \\
\omega_{i b y}^{b} \\
\omega_{i b z}^{b}
\end{array}\right]+\left[\begin{array}{c}
\mathrm{gB}_{x} \\
\mathrm{gB}_{y} \\
\mathrm{gB}_{z}
\end{array}\right]\right) \\
& =-\mathbf{C}_{b}^{n}\left(\delta \mathbf{K}_{G} \boldsymbol{\omega}_{i b}^{b}+\mathrm{gB}\right) .
\end{aligned}
$$

When the airframe turns, the angular velocity of the Earth and the platform are small relative to the IMU rotation rate. So we ignore the influence of angular velocity of the Earth and the platform on the attitude error; the attitude error equation is further simplified [14]:

$$
\dot{\boldsymbol{\varphi}}=-\mathbf{C}_{b}^{n}\left(\delta \mathbf{K}_{G}\left(\boldsymbol{\omega}_{\mathrm{in}}^{b}+\boldsymbol{\omega}_{n b}^{b}\right)+\mathrm{gB}\right) \approx-\mathbf{C}_{b}^{n}\left(\delta \mathbf{K}_{G} \boldsymbol{\omega}_{n b}^{b}+\mathrm{gB}\right) .
$$


When the system only changes the pitch angle, the roll angle and heading angle change could be assumed to be zero, then

$$
\boldsymbol{\omega}_{n b}^{b}=\left[\begin{array}{lll}
\omega_{\mathrm{x}} & 0 & 0
\end{array}\right]^{T}, \mathbf{C}_{b}^{n} \approx\left[\begin{array}{ccc}
1 & 0 & 0 \\
0 & \cos \theta & -\sin \theta \\
0 & \sin \theta & \cos \theta
\end{array}\right]
$$

Substituting (7) into (6),

$$
\begin{gathered}
\dot{\boldsymbol{\varphi}}=-\omega_{\mathrm{x}} \cdot\left[\begin{array}{c}
\mathrm{gSF}_{\mathrm{x}} \\
\cos \theta \cdot \mathrm{gMA}_{\mathrm{yx}}-\sin \theta \cdot \mathrm{gMA}_{\mathrm{zx}} \\
\cos \theta \cdot \mathrm{gMA}_{\mathrm{zx}}+\sin \theta \cdot \mathrm{gMA}_{\mathrm{yx}}
\end{array}\right] \\
-\left[\begin{array}{c}
\mathrm{gB}_{\mathrm{x}} \\
\cos \theta \cdot \mathrm{gB}_{y}-\sin \theta \cdot \mathrm{gB}_{\mathrm{z}} \\
\cos \theta \cdot \mathrm{gB}_{\mathrm{z}}+\sin \theta \cdot \mathrm{gB}_{y}
\end{array}\right] .
\end{gathered}
$$

Combined with the gyroscope error parameters given above and (8), the influence of gyroscope scale factor error $\mathrm{gSF}_{x}$ on attitude error is greater than that of gyroscope bias $\mathrm{gB}_{x}$ on attitude error when $\left|\omega_{x}\right|>0.93^{\circ} / \mathrm{s}$; the influence of gyroscope misalignment errors $\mathrm{gMA}_{y x}$ and $\mathrm{gMA}_{z x}$ on attitude error is greater than that of gyro bias $\mathrm{gB}_{x}$ and $\mathrm{gB}_{z}$ on attitude error when $\left|\omega_{x}\right|>1.43^{\circ} / \mathrm{s}$. Therefore, when the body pitch angle changes, the influence of gyroscope scale factor error and misalignment error on attitude error cannot be ignored.

Similarly, when the system roll angle changes or heading angle changes, then $\omega_{n b}^{b}$ is

$$
\boldsymbol{\omega}_{n b}^{b}=\left[\begin{array}{lll}
0 & \omega_{\mathrm{y}} & 0
\end{array}\right]^{T} \text { or } \boldsymbol{\omega}_{n b}^{b}=\left[\begin{array}{lll}
0 & 0 & \omega_{\mathrm{z}}
\end{array}\right]^{T}
$$

Substituting (9) into (6), we can get the same conclusion.

2.3.2. Error Analysis of Velocity and Position. The most common movements of the aircraft are uniform motion and accelerated motion, this paper mainly analyzes the influence of the accelerometer errors on position error and velocity error in these two kinds of motion. To simplify the analysis, this paper also does not consider other error terms, so velocity error equation can be simplified as

$$
\begin{aligned}
\delta \dot{\mathbf{v}}^{n} & =\mathbf{C}_{b}^{n}\left(\left[\begin{array}{ccc}
\mathrm{aSF}_{x} & \mathrm{aMA}_{x y} & \mathrm{aMA}_{x z} \\
\mathrm{aMA}_{y x} & \mathrm{aSF}_{y} & \mathrm{aMA}_{y z} \\
\mathrm{aMA}_{z x} & \mathrm{aMA}_{z y} & \mathrm{aSF}_{z}
\end{array}\right]\left[\begin{array}{c}
f_{x}^{b} \\
f_{y}^{b} \\
f_{z}^{b}
\end{array}\right]+\left[\begin{array}{c}
\mathrm{aB}_{x} \\
\mathrm{aB}_{y} \\
\mathrm{aB}_{z}
\end{array}\right]\right) \\
& =\mathbf{C}_{b}^{n}\left(\delta \mathbf{K}_{A} \mathbf{f}_{s f}^{b}+\mathrm{aB}\right) .
\end{aligned}
$$

When the system only changes the pitch angle, the roll angle and heading angle change could be assumed to be zero; the attitude matrix $\mathbf{C}_{b}^{n}$ can be simplified as

$$
\mathbf{C}_{b}^{n}=\left[\begin{array}{ccc}
1 & 0 & 0 \\
0 & \cos \theta & -\sin \theta \\
0 & \sin \theta & \cos \theta
\end{array}\right]
$$

Substituting (11) into (10),

$$
\begin{aligned}
& \delta \dot{\mathbf{v}}^{n}=\left[\begin{array}{c}
\delta \dot{v}_{E}^{n} \\
\delta \dot{v}_{N}^{n} \\
\delta \dot{v}_{U}^{n}
\end{array}\right] \approx {\left[\begin{array}{c}
\mathrm{aB}_{\mathrm{x}} \\
\cos \theta \cdot \mathrm{aB}_{y}-\sin \theta \cdot \mathrm{aB}_{\mathrm{z}} \\
\cos \theta \cdot \mathrm{aB}_{\mathrm{z}}+\sin \theta \cdot \mathrm{aB}_{y}
\end{array}\right] } \\
& \mathrm{aSF}_{\mathrm{x}} \\
&+f_{x} \cdot\left[\begin{array}{c}
\cos \theta \cdot \mathrm{aMA}_{y x}-\sin \theta \cdot \mathrm{aMA}_{\mathrm{zx}} \\
\sin \theta \cdot \mathrm{aMA}_{y x}+\cos \theta \cdot \mathrm{aMA}_{\mathrm{zx}}
\end{array}\right] \\
&+f_{y} \cdot\left[\begin{array}{c}
\mathrm{aMA} \mathrm{A}_{x y} \\
\cos \theta \cdot \mathrm{aSF}_{y}-\sin \theta \cdot \mathrm{aMA}_{z y} \\
\sin \theta \cdot \mathrm{aSF}_{y}+\cos \theta \cdot \mathrm{aMA}_{z y}
\end{array}\right] \\
& \mathrm{aMA}_{x z} \\
&+g \cdot\left[\begin{array}{c}
\cos \theta \cdot \mathrm{aMA}_{y z}-\sin \theta \cdot \mathrm{aSF}_{z} \\
\sin \theta \cdot \mathrm{aMA}_{y z}+\cos \theta \cdot \mathrm{aSF}_{z}
\end{array}\right]
\end{aligned}
$$

In uniform motion $\left(f_{x}=f_{y} \approx 0\right)$, according to the accelerometer error parameters and (12), we can conclude that aM $\mathrm{A} \cdot g \approx 194 \mu \mathrm{g}<\mathrm{aB}=500 \mu \mathrm{g}$. The influence of accelerometer misalignment errors $\mathrm{aMA}_{x z}$ and $\mathrm{aMA}_{y z}$ on the east and north velocity errors is about $40 \%$ of the bias $\mathrm{aB}_{x}$ and $\mathrm{aB}_{y}$. In addition, $\mathrm{aSF}_{z} \cdot g \approx 300 \mu \mathrm{g}<\mathrm{aB}_{z}=500 \mu \mathrm{g}$. The influence of the accelerometer scale factor error $\mathrm{aSF}_{z}$ on upward velocity error is about $60 \%$ of accelerometer bias $\mathrm{aB}_{z}$. Therefore, the influence of the accelerometer scale factor error and misalignment error on velocity error cannot be ignored in uniform motion.

In accelerated motion $\left(f_{x} \neq 0, f_{y} \neq 0\right)$, according to the accelerometer error parameters and (12), we can conclude that when $\left|f_{y}\right|>1.67 \mathrm{~g}$ and $\left|f_{z}\right|>1.67 \mathrm{~g}$, the influence of the accelerometer scale factor errors $\mathrm{aSF}_{y}$ and $\mathrm{aSF}_{z}$ on the north velocity error and upward velocity error is greater than that of accelerometer bias $\mathrm{aB}_{y}$ and $\mathrm{aB}_{z}$. When $\left|f_{y}\right|>2.57 \mathrm{~g}$ and $\left|f_{z}\right|>2.57 \mathrm{~g}$, the influence of the accelerometer misalignment errors $\mathrm{aMA}_{z y}$ and $\mathrm{aMA}_{y z}$ on the north velocity error and upward velocity error is greater than that of accelerometer bias $\mathrm{aB}_{z}$ and $\mathrm{aB}_{y}$. In the actual motion, the acceleration of aircraft is about $0.3 \mathrm{~g}$. According to the analysis above, the influence of the accelerometer scale 


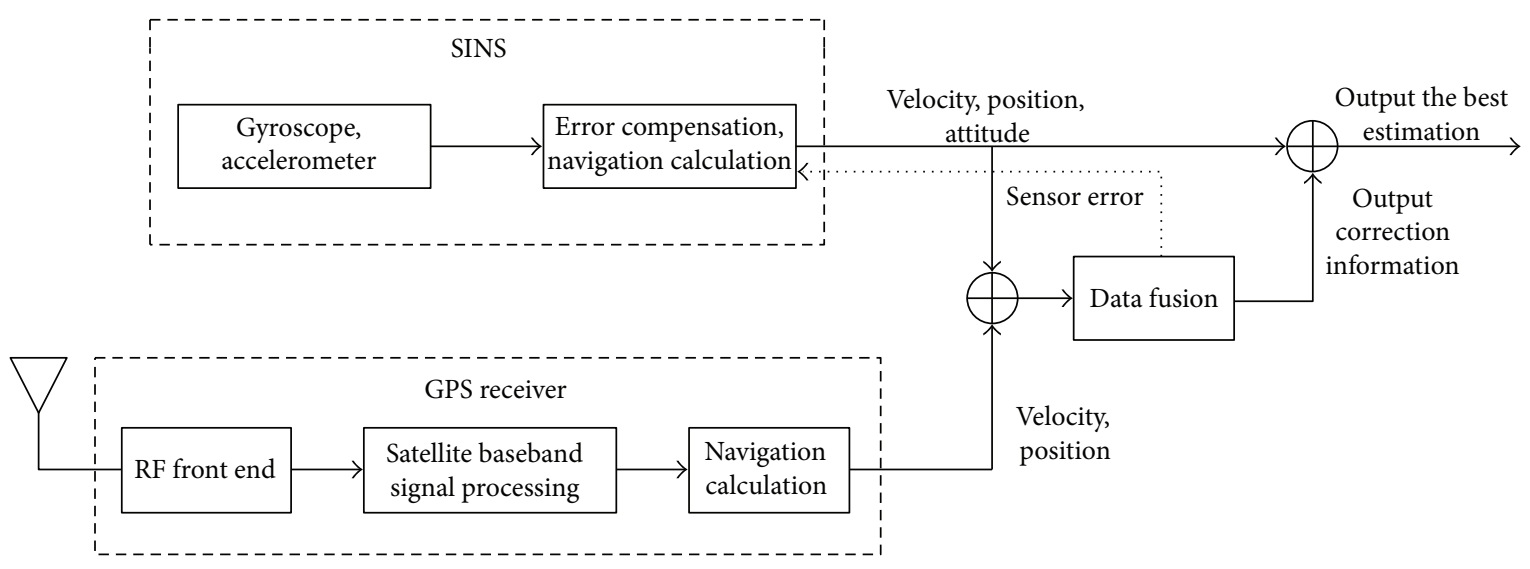

FIGURE 1: INS/GPS integrated navigation schematic.

factor error on velocity error is about $18 \%$ of the accelerometer bias and the influence of accelerometer misalignment error on velocity error is $12 \%$ of the accelerometer bias in accelerated movement.

Similarly, when the system's roll angle changes or heading angle changes, attitude matrix $\mathbf{C}_{b}^{n}$ is

$\mathbf{C}_{b}^{n} \approx\left[\begin{array}{ccc}\cos \gamma & 0 & \sin \gamma \\ 0 & 1 & 0 \\ -\sin \gamma & 0 & \cos \gamma\end{array}\right]$ or $\mathbf{C}_{b}^{n} \approx\left[\begin{array}{ccc}\cos \psi & \sin \psi & 0 \\ -\sin \psi & \cos \psi & 0 \\ 0 & 0 & 1\end{array}\right]$

Substituting (13) into (10), we can get the same conclusion.

In summary, the influence of scale factor error and misalignment error of gyroscope and accelerometer on navigation cannot be ignored.

\section{Model Establishment}

3.1. INS/GPS Integrated Navigation Model. From what has been analyzed above, we can conclude that the influence of scale factor error and misalignment error on navigation cannot be ignored in airborne navigation. Therefore, the scale factor error and misalignment error need to be considered in the INS/GPS integrated error model. In this paper, INS/GPS integrated navigation is realized by using Kalman filter. The position and velocity differences between GPS and INS are taken as measurement errors. IMU errors and navigation errors can be online estimated and compensated, so the high navigation accuracy can be acquired. INS/GPS integrated navigation schematic diagram is shown in Figure 1.

3.1.1. Error State Model of Integrated Navigation. The integrated system error model can be expressed as

$$
\dot{\mathbf{X}}(t)=\mathbf{F}(t) \mathbf{X}(t)+\mathbf{G}(t) \mathbf{W}(t)
$$

$\mathbf{X}(t)$ is the 33-dimensional error vector of integrated system which can be expressed as

$$
\begin{aligned}
\mathbf{X}(t)=[ & \delta L \delta \lambda \delta h \delta v_{E}^{n} \delta v_{N}^{n} \delta v_{U}^{n} \boldsymbol{\varphi}_{E} \boldsymbol{\varphi}_{N} \boldsymbol{\varphi}_{U} \mathrm{aB}_{x} \mathrm{aB}_{y} \mathrm{aB}_{z} \mathrm{gB}_{x} \mathrm{gB}_{y} \\
& \mathrm{gB}_{z} \mathrm{aSF}_{x} \mathrm{aSF}_{y} \mathrm{aSF}_{z} \mathrm{aMA}_{x y} \mathrm{aMA}_{x z} \mathrm{aMA}_{y x} \mathrm{aMA}_{y z} \\
& \mathrm{aMA}_{z x} \mathrm{aMA}_{z y} \mathrm{gSF}_{x} \mathrm{gSF}_{y} \mathrm{gSF}_{z} \mathrm{gMA}_{x y} \mathrm{gMA}_{x z} \mathrm{gMA}_{y x} \\
& \left.\mathrm{gMA}_{y z} \mathrm{gMA}_{z x} \mathrm{gMA}_{z y}\right]^{T},
\end{aligned}
$$

$\mathbf{W}(t)$ is the system noise model which can be expressed as $\mathbf{W}(t)=\left[\begin{array}{llllllll}0_{1 \times 3} & \mathrm{aW}_{x} & \mathrm{aW}_{y} & \mathrm{aW}_{z} & \mathrm{gW}_{x} & \mathrm{gW}_{y} & \mathrm{gW}_{z} & 0_{1 \times 24}\end{array}\right]^{\mathrm{T}}$,

where $\mathrm{aW}_{x}, \mathrm{aW}_{y}$, and $\mathrm{aW}_{z}$ are accelerometer noises, $\mathrm{gW}_{x}$, $\mathrm{gW}_{y}$, and $\mathrm{gW}_{z}$ are gyroscope noises.

$\mathbf{G}(t)$ is the noise driving matrix of integrated system,

$$
\mathbf{G}(t)=\left[\begin{array}{cccc}
0_{3 \times 3} & 0_{3 \times 3} & 0_{3 \times 3} & \\
0_{3 \times 3} & \mathbf{C}_{b}^{n} & 0_{3 \times 3} & 0_{9 \times 24} \\
0_{3 \times 3} & 0_{3 \times 3} & \mathbf{C}_{b}^{n} & \\
& 0_{24 \times 9} & & 0_{24 \times 24}
\end{array}\right] .
$$

3.1.2. Measurement Model of Integrated Navigation. The velocity and position differences between GPS and INS are taken as measurement errors in the process of integrated navigation. So the measurement equation can be expressed as

$$
\begin{aligned}
\mathbf{Z}(t) & =\left[\begin{array}{l}
\mathbf{H}_{p} \\
\mathbf{H}_{V}
\end{array}\right] \mathbf{X}(t)+\left[\begin{array}{c}
\mathbf{V}_{p} \\
\mathbf{V}_{V}
\end{array}\right], \\
\mathbf{H}_{p} & =\left[\begin{array}{cccc}
0 & R \cos L & 0 \\
R & 0 & 0 & 0_{3 \times 30} \\
0 & 0 & 0 \vdots
\end{array}\right], \\
\mathbf{H}_{V} & =\left[\begin{array}{lll}
0_{3 \times 3} & \mathbf{I}_{3} & 0_{3 \times 27}
\end{array}\right] .
\end{aligned}
$$

$\mathbf{V}_{P}$ and $\mathbf{V}_{V}$ are the measurement noises of position and velocity, respectively [15-17]. 
TABLE 1: The flight stages of aircraft.

\begin{tabular}{lcccccccc}
\hline Flight stage & Duration $(\mathrm{s})$ & Acceleration $\left(\mathrm{m} / \mathrm{s}^{2}\right)$ & Yaw $\left(^{\circ}\right)$ & Yaw rate $\left({ }^{\circ} / \mathrm{s}\right)$ & Pitch $\left(^{\circ}\right)$ & Pitch rate $\left({ }^{\circ} / \mathrm{s}\right)$ & Roll $\left(^{\circ}\right)$ & Roll rate $\left({ }^{\circ} / \mathrm{s}\right)$ \\
\hline Glide & 20 & 2.5 & 45 & 0 & 0 & 0 & 0 & 0 \\
Preparation for climbing & 5 & 0 & 45 & 0 & 0 & 6 & 0 & 0 \\
Climbing & 100 & 0 & 45 & 0 & 30 & 0 & 0 & 0 \\
Transformation level & 5 & 0 & 45 & 0 & 30 & -6 & 0 & 0 \\
Uniform flight & 200 & 0 & 45 & 0 & 0 & 0 & 0 & 0 \\
Tilt to the left & 20 & 0 & 45 & 0 & 0 & 0 & 0 & 1 \\
Circle to the left & 45 & 0 & 45 & 2 & 0 & 0 & 20 & 0 \\
Exit circle & 20 & 0 & 135 & 0 & 0 & 0 & 20 & -1 \\
Uniform flight & 285 & 0 & 135 & 0 & 0 & 0 & 0 & 0 \\
\hline
\end{tabular}

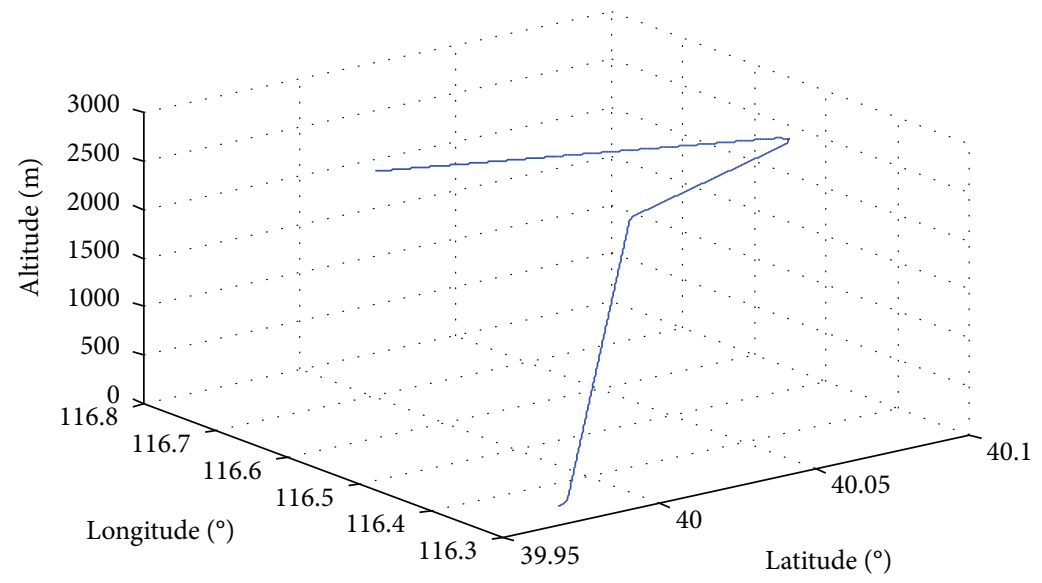

Figure 2: The flight trajectory of aircraft.

3.2. Airborne INS/GPS Integrated System Optimization. Scale factor error and misalignment error are added in the new integrated model. However, the scale factor error and misalignment error cannot be observed completely. It is difficult to obtain the desired estimation results if the estimated states cannot be observed. So the observability of the scale factor error and misalignment error is analyzed by a combined typical airborne trajectory. Based on the analysis of observability, we delete unobservable error states and get the optimized integrated navigation model.

3.2.1. Observability Analysis. In this paper, the movement of aircraft is divided into the following three typical processes: straight flight, climbing flight, and turning flight. Straight flight includes uniform motion and accelerated motion. Climbing flight includes preparation for climbing, climbing, and transformation level. Turning flight includes tilting and spiral. Flight trajectory consists of the three processes above. Considering the complexity of the procedure, this paper does not simulate the whole flight process but chooses nine typical stages $[18,19]$. The flight stages of aircraft and simulation trajectory are shown in Table 1 and Figure 2.

With the combined typical flight trajectory above, according to the eigenvalues of the error covariance matrix, the observability of the scale factor error and misalignment error of the gyroscope and accelerometer is analyzed in different maneuvering conditions. And the influence of different maneuvering conditions on observability of each error term is analyzed. The eigenvalues of the covariance matrix can reflect whether the system state estimation is good or bad. The smaller the eigenvalue is, the smaller the estimated variance of the corresponding state is and the better the degree of observability is. Otherwise, the estimation accuracy is low and the degree of observability is poor.

Figures 3 and 4 are the normalized eigenvalues of the corresponding errors in the covariance matrix during the whole motion. Tables 2 and 3 are the normalized covariance of scale error and misalignment error of gyroscope and accelerometer.

As can be seen from Figure 3 and Table 2, the scale factor error and misalignment error of gyroscope are not observable during gliding. When climbing, the degree of observability of $\mathrm{gSF}_{x}$ is increased. In a uniform flight, the flight time is long and the observability of $\mathrm{gSF}_{x}$ and $\mathrm{gMA}_{y x}$ is significantly increased. The degree of observability of $\mathrm{gSF}_{y}$ and $\mathrm{gMA}_{y z}$ is increased when circling to the left and the degree of observability of $\mathrm{gMA}_{x z}$ is increased during circle exit. It can be seen that rotational maneuvering has a good incentive 


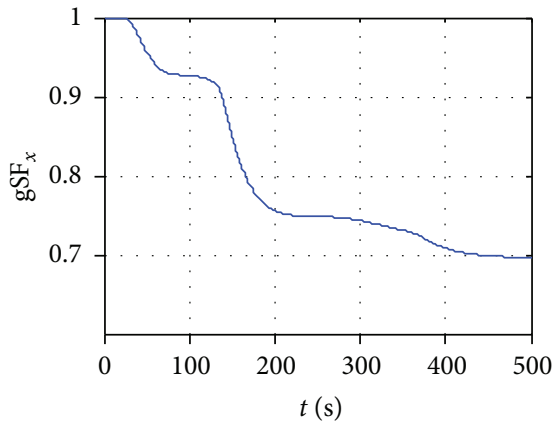

(a)

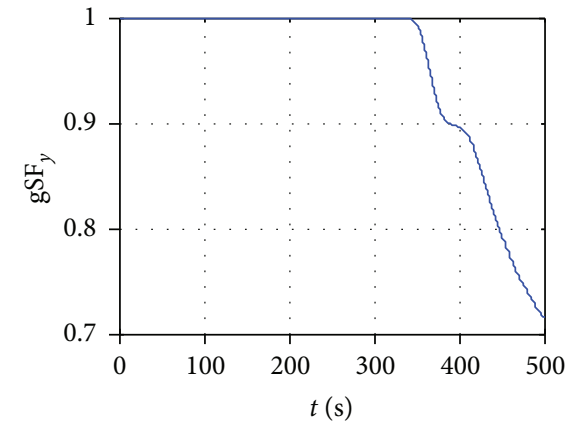

(b)

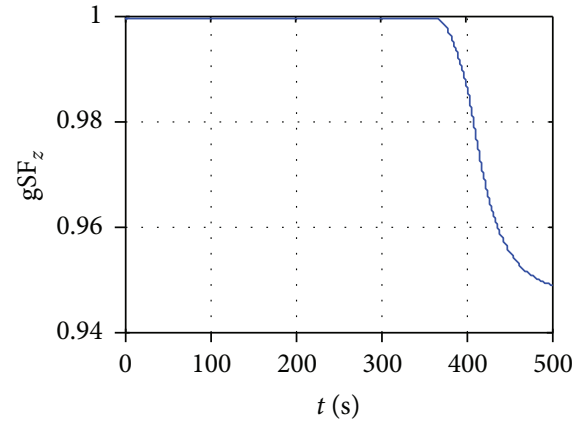

(c)

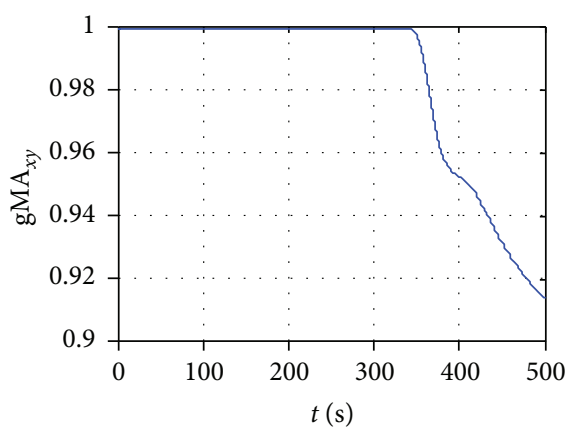

(d)

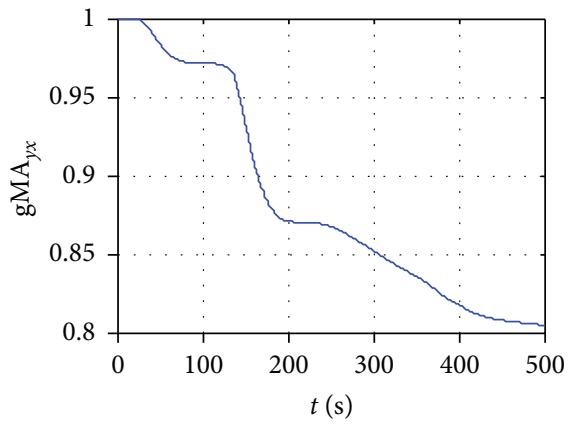

(f)

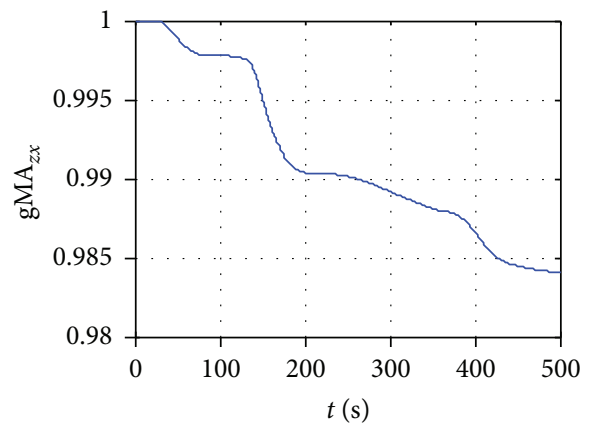

(h)

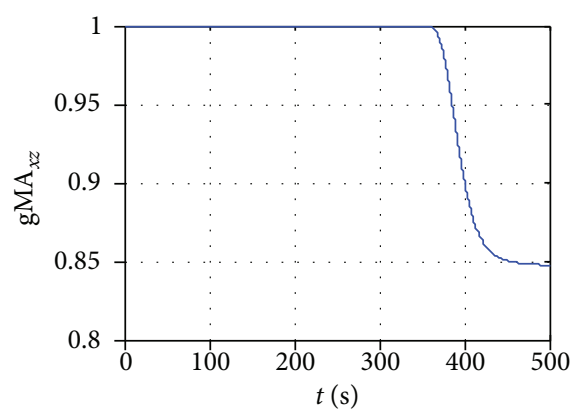

(e)

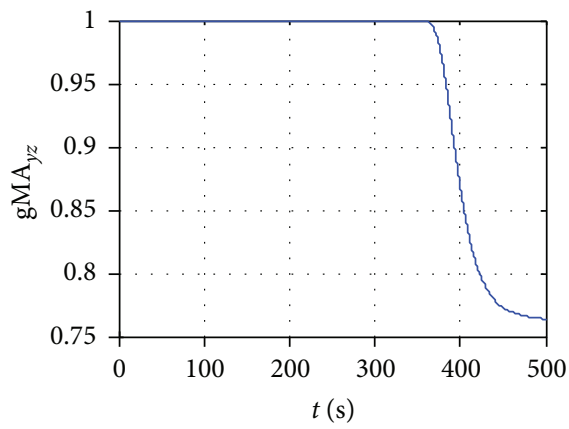

(g)

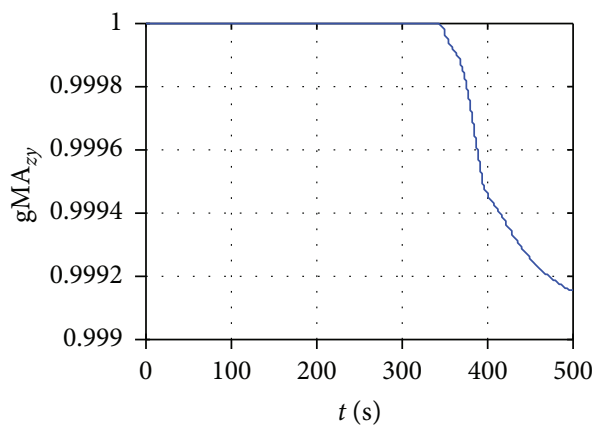

(i)

FIGURE 3: Eigenvalues of covariance matrix corresponding to gyroscope errors.

for $\mathrm{gSF}_{y}, \mathrm{gMA}_{y z}$, and $\mathrm{gMA}_{x z}$. So $\mathrm{gSF}_{x}, \mathrm{gSF}_{y}, \mathrm{gMA}_{x z}$, $\mathrm{gMA}_{y x}$, and $\mathrm{gMA}_{y z}$ are observable. Moreover, at the end of the whole movement, the normalized covariance of $\mathrm{gSF}_{z}, \mathrm{gMA}_{x y}, \mathrm{gMA}_{z x}$, and $\mathrm{gMA}_{z y}$ are decreased not obviously. In summary, $\mathrm{gSF}_{z}, \mathrm{gMA}_{x y}, \mathrm{gMA}_{z x}$, and $\mathrm{gMA}_{z y}$ of gyroscope errors are unobservable.
As can be seen from Figure 4 and Table 3, the degree of observability of scale factor error $\mathrm{aSF}_{z}$ is increased during accelerated gliding. The change of the observability degree of scale factor error and misalignment error is not obvious during climbing and transformation level. In a uniform flight, the degree of observability of 


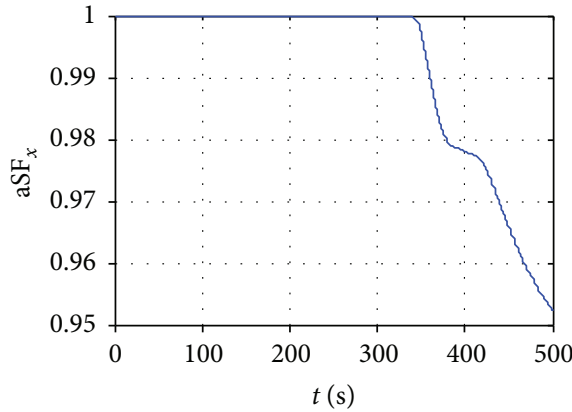

(a)

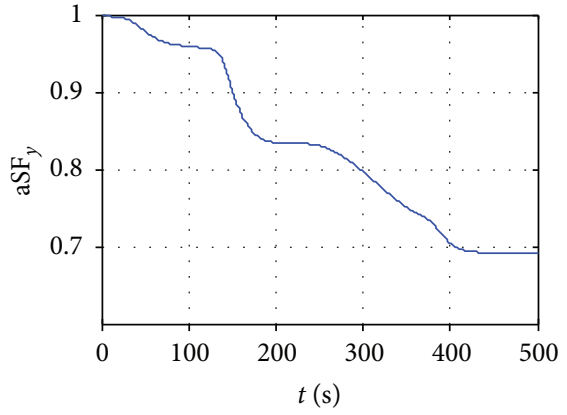

(b)

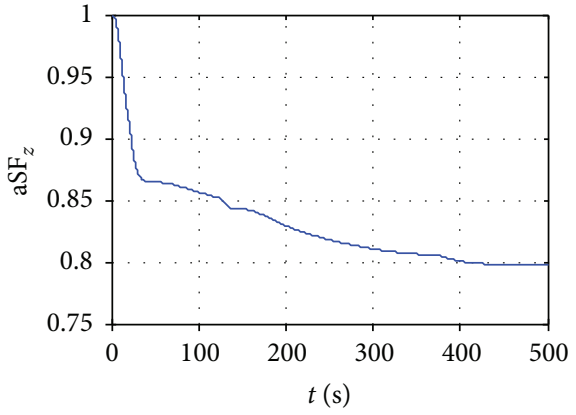

(c)

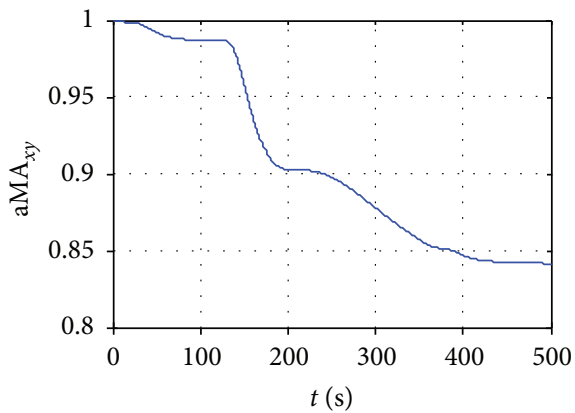

(d)

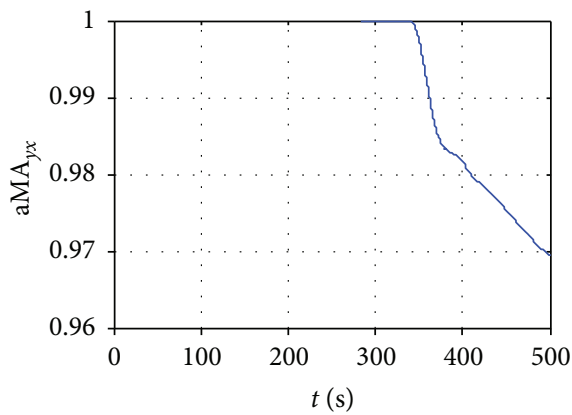

(f)

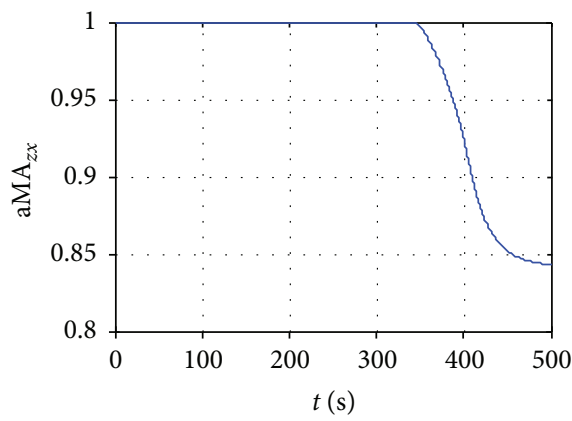

(h)

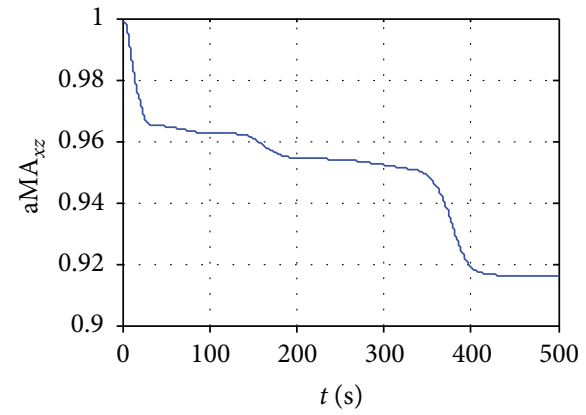

(e)

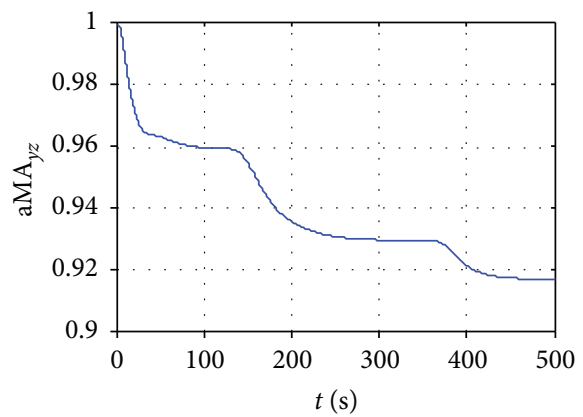

$(\mathrm{g})$

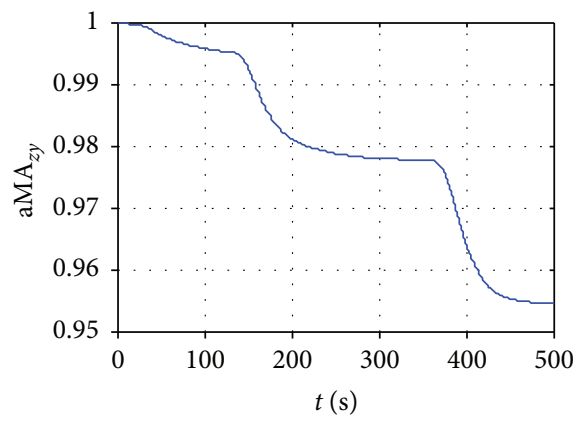

(i)

FIGURE 4: Eigenvalues of covariance matrix corresponding to accelerometer errors.

$\mathrm{aSF}_{y}$ and $\mathrm{aMA}_{x y}$ is significantly increased. The degree of observability of $\mathrm{aMA}_{z x}$ is increased during circling to the left and exit circle. So $\mathrm{aSF}_{y}, \mathrm{aSF}_{z}, \mathrm{aMA}_{x y}$, and $\mathrm{aMA}_{z x}$ are observable. Moreover, at the end of the whole movement, the normalized covariance of $\mathrm{aSF}_{x}, \mathrm{aMA}_{x z}, \mathrm{aMA}_{y x}, \mathrm{aMA}_{y z}$, and $\mathrm{aMA}_{z y}$ are decreased not obviously. In summary, $\mathrm{aSF}_{x}$,
$\mathrm{aMA}_{x z}, \mathrm{aMA}_{y x}, \mathrm{aMA}_{y z}$, and $\mathrm{aMA}_{z y}$ of accelerometer errors are unobservable.

3.2.2. Optimization of Integrated System. As can be seen from the observability analysis results, the error states $\mathrm{gSF}_{z}, \mathrm{gMA}_{x y}, \mathrm{gMA}_{z x}, \mathrm{gMA}_{z y}, \mathrm{aSF}_{x}, \mathrm{aMA}_{x z}, \mathrm{aMA}_{y x}, \mathrm{aMA}_{y z}$, 
TABLE 2: Normalized covariance of gyroscope scale factor and misalignment.

\begin{tabular}{lcccccccccc}
\hline Error state & Initial value & Glide & $\begin{array}{c}\text { Preparation } \\
\text { for climbing }\end{array}$ & Climbing & $\begin{array}{c}\text { Transformation } \\
\text { level }\end{array}$ & $\begin{array}{c}\text { Uniform } \\
\text { flight }\end{array}$ & $\begin{array}{c}\text { Tilt to } \\
\text { the left }\end{array}$ & $\begin{array}{c}\text { Circle to } \\
\text { the left }\end{array}$ & $\begin{array}{c}\text { Exit circle } \\
\text { Final value }\end{array}$ \\
\hline $\mathrm{gSF}_{x}$ & 1.00 & 1.00 & 0.99 & 0.91 & 0.91 & 0.72 & 0.72 & 0.70 & 0.69 & 0.69 \\
$\mathrm{gSF}_{y}$ & 1.00 & 1.00 & 1.00 & 1.00 & 1.00 & 1.00 & 0.99 & 0.88 & 0.87 & 0.71 \\
$\mathrm{gSF}_{z}$ & 1.00 & 1.00 & 1.00 & 1.00 & 1.00 & 1.00 & 1.00 & 0.99 & 0.97 & 0.95 \\
$\mathrm{gMA}_{x y}$ & 1.00 & 1.00 & 1.00 & 1.00 & 1.00 & 1.00 & 0.99 & 0.94 & 0.94 & 0.92 \\
$\operatorname{gMA}_{x z}$ & 1.00 & 1.00 & 1.00 & 1.00 & 1.00 & 1.00 & 1.00 & 0.91 & 0.86 & 0.85 \\
$\operatorname{gMA}_{y x}$ & 1.00 & 1.00 & 0.99 & 0.96 & 0.96 & 0.83 & 0.82 & 0.80 & 0.80 & 0.80 \\
$\operatorname{gMA}_{y z}$ & 1.00 & 1.00 & 1.00 & 1.00 & 1.00 & 1.00 & 1.00 & 0.88 & 0.80 & 0.76 \\
$\operatorname{gMA}_{z x}$ & 1.00 & 1.00 & 1.00 & 0.99 & 0.99 & 0.98 & 0.98 & 0.98 & 0.98 & 0.98 \\
$\operatorname{gMA}_{z y}$ & 1.00 & 1.00 & 1.00 & 1.00 & 1.00 & 1.00 & 1.00 & 0.99 & 0.99 & 0.99 \\
\hline
\end{tabular}

TABLE 3: Normalized covariance of accelerometer scale factor and misalignment.

\begin{tabular}{lcccccccccc}
\hline Error state & Initial value & Glide & $\begin{array}{c}\text { Preparation } \\
\text { for climbing }\end{array}$ & Climbing & $\begin{array}{c}\text { Transformation } \\
\text { level }\end{array}$ & $\begin{array}{c}\text { Uniform } \\
\text { flight }\end{array}$ & Tilt to the left & $\begin{array}{c}\text { Circle to } \\
\text { the left }\end{array}$ & $\begin{array}{c}\text { Exit circle } \\
\text { Final value }\end{array}$ \\
\hline $\mathrm{aSF}_{x}$ & 1.00 & 1.00 & 1.00 & 1.00 & 1.00 & 1.00 & 0.99 & 0.98 & 0.95 & 0.95 \\
$\mathrm{aSF}_{y}$ & 1.00 & 0.99 & 0.99 & 0.95 & 0.95 & 0.75 & 0.73 & 0.69 & 0.69 & 0.69 \\
$\mathrm{aSF}_{z}$ & 1.00 & 0.91 & 0.88 & 0.85 & 0.84 & 0.80 & 0.80 & 0.80 & 0.79 & 0.79 \\
$\mathrm{aMA}_{x y}$ & 1.00 & 0.99 & 0.99 & 0.99 & 0.99 & 0.85 & 0.84 & 0.83 & 0.83 & 0.83 \\
$\mathrm{aMA}_{x z}$ & 1.00 & 0.97 & 0.96 & 0.96 & 0.96 & 0.94 & 0.94 & 0.92 & 0.92 & 0.92 \\
$\mathrm{aMA}_{y x}$ & 1.00 & 1.00 & 1.00 & 1.00 & 1.00 & 1.00 & 0.99 & 0.98 & 0.97 & 0.97 \\
$\mathrm{aMA}_{y z}$ & 1.00 & 0.97 & 0.96 & 0.95 & 0.95 & 0.92 & 0.92 & 0.92 & 0.92 & 0.92 \\
$\mathrm{aMA}_{z x}$ & 1.00 & 1.00 & 1.00 & 1.00 & 1.00 & 1.00 & 0.99 & 0.93 & 0.88 & 0.84 \\
$\mathrm{aMA}_{z y}$ & 1.00 & 1.00 & 1.00 & 1.00 & 1.00 & 0.98 & 0.98 & 0.97 & 0.96 & 0.95 \\
\hline
\end{tabular}

and $\mathrm{aMA}_{z y}$ are unobservable. After the unobservable errors are deleted, the dimensions of the error states is reduced from 33 to 24 and the optimized error state vector of the integrated system is

$$
\begin{aligned}
\mathbf{X}(t)=[ & \delta L \delta \lambda \delta h \delta v_{E}^{n} \delta v_{N}^{n} \delta v_{U}^{n} \boldsymbol{\varphi}_{E} \boldsymbol{\varphi}_{N} \boldsymbol{\varphi}_{U} \mathrm{aB}_{x} \mathrm{aB}_{y} \mathrm{aB}_{z} \mathrm{gB}_{x} \mathrm{gB}_{y} \\
& \mathrm{gB}_{z} \mathrm{aSF}_{y} \mathrm{aSF}_{z} \mathrm{aMA}_{x y} \mathrm{aMA}_{z x} \mathrm{gSF}_{x} \mathrm{gSF}_{y} \mathrm{gMA}_{x z} \\
& \left.\mathrm{gMA}_{y x} \mathrm{gMA}_{y z}\right]^{T} .
\end{aligned}
$$

So the system noise vector and the noise driving matrix of the integrated system are

$$
\begin{aligned}
& \mathbf{W}(t)= {\left[0_{1 \times 3} \mathrm{aW}_{x} \mathrm{aW}_{y} \mathrm{aW}_{z} \mathrm{gW}_{x} \mathrm{gW}_{y} \mathrm{gW}_{z} 0_{1 \times 15}\right], } \\
& \mathbf{G}(t)=\left[\begin{array}{cccc}
0_{3 \times 3} & 0_{3 \times 3} & 0_{3 \times 3} & \\
0_{3 \times 3} & \mathbf{C}_{b}^{n} & 0_{3 \times 3} & 0_{9 \times 15} \\
0_{3 \times 3} & 0_{3 \times 3} & \mathbf{C}_{b}^{n} & \\
& 0_{15 \times 9} & & 0_{15 \times 15}
\end{array}\right]
\end{aligned}
$$

The measurement matrix is expressed as

$$
\begin{aligned}
& \mathbf{H}_{p}=\left[\begin{array}{cccc}
0 & R \cos L & 0 \vdots \\
R & 0 & 0 \vdots & 0_{3 \times 21} \\
0 & 0 & 0 \vdots
\end{array}\right], \\
& \mathbf{H}_{v}=\left[\begin{array}{lll}
0_{3 \times 3} & \mathbf{I}_{3} & 0_{3 \times 18}
\end{array}\right] .
\end{aligned}
$$

In this way, the optimized integrated model is obtained, and then the simulation and turntable test are used to verify the optimized model, respectively.

\section{Model Verification}

4.1. Simulation Verification. In this paper, numerical simulation is used to verify the validity and correctness of the proposed INS/GPS integrated model and then compare it with traditional integrated model.

The error parameters of IMU and GPS are as follows:

(1) Gyroscope

(i) Bias: $1^{\circ} / \mathrm{h}$; noise: $0.05^{\circ} / \sqrt{\mathrm{h}}$ 
(ii) Scale factor error: $300 \mathrm{ppm}$; misalignment error: $40^{\prime \prime}$

(2) Accelerometer

(i) Bias: $500 \mu \mathrm{g}$; noise: $100 \mu \mathrm{g} / \sqrt{\mathrm{Hz}}$

(ii) Scale factor error: $300 \mathrm{ppm}$; misalignment error: $40^{\prime \prime}$

(3) GPS Receiver

(i) Position error: level $3 \mathrm{~m}$, vertical $5 \mathrm{~m}$

(ii) Velocity error: level $0.05 \mathrm{~m} / \mathrm{s}$, vertical $0.05 \mathrm{~m} / \mathrm{s}$

The simulation time is 700 seconds, the first 500 seconds for INS/GPS integrated navigation. GPS failure after 500 seconds, the receiver cannot output velocity and position information. At this time, integrated system cannot update measurement equation and turns into inertial navigation mode. The simulation results are as follows, Figure 5 shows the estimation of gyroscope bias, scale factor error, and misalignment error in integrated navigation. Figure 6 shows the estimation of accelerometer bias, scale factor error, and misalignment error in integrated navigation. Figure 7 shows the true value, estimation of position and position error of the traditional integrated navigation model, and the proposed navigation model in the whole simulation process, including the east position, the north position, and the upward position.

From the simulation results above, the set errors of gyroscope bias, scale factor, and misalignment are $1^{\circ} / \mathrm{h}, 300 \mathrm{ppm}$, and $40^{\prime \prime}$, respectively. Figure 3 shows that the error estimation of the gyroscope are $0.96^{\circ} / \mathrm{h}, 305 \mathrm{ppm}$, and $42.8^{\prime \prime}$, respectively. The set errors of accelerometer bias, scale factor, and misalignment are $500 \mu \mathrm{g}, 300 \mathrm{ppm}$, and $40^{\prime \prime}$, respectively. Figure 4 shows that the error estimation of the accelerometer are $482 \mu \mathrm{g}, 297 \mathrm{ppm}$, and $43^{\prime \prime}$, respectively. Therefore, the observable errors of IMU are effectively estimated in integrated navigation.

GPS signal is lost after 500 seconds; system conducted 200 seconds inertial navigation at 700 seconds. Figure 7 shows that the east, north, and upward position errors of the traditional model are $380 \mathrm{~m}, 231.4 \mathrm{~m}$, and $126.1 \mathrm{~m}$, respectively. The east, north, and upward position errors of the proposed model are $271.2 \mathrm{~m}, 175.1 \mathrm{~m}$, and $111.5 \mathrm{~m}$, respectively. The navigation accuracy of the east, north, and upward positions of the proposed model improved by $28.6 \%, 24.3 \%$, and $8.3 \%$, respectively.

4.2. Turntable Test. Numerical simulation has proved the validity of the proposed integrated navigation method. In order to further verify the effectiveness of the method in actual integrated navigation system, turntable test is designed on the basis of numerical simulation. Test equipment include INS/GPS integrated navigation system, turntable, two-way DC power supply $(0 \sim 30 \mathrm{~V}, 0 \sim 3 \mathrm{~A})$, and data acquisition

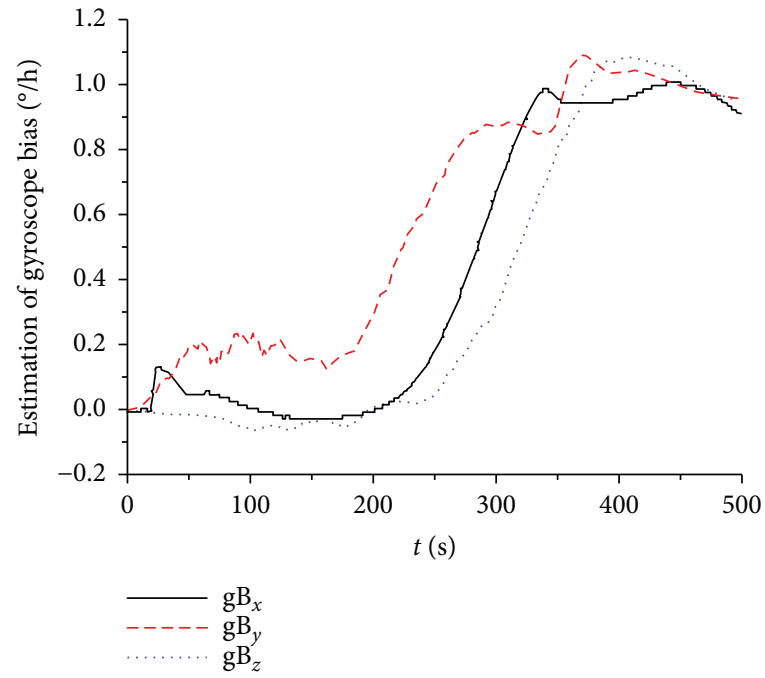

(a)

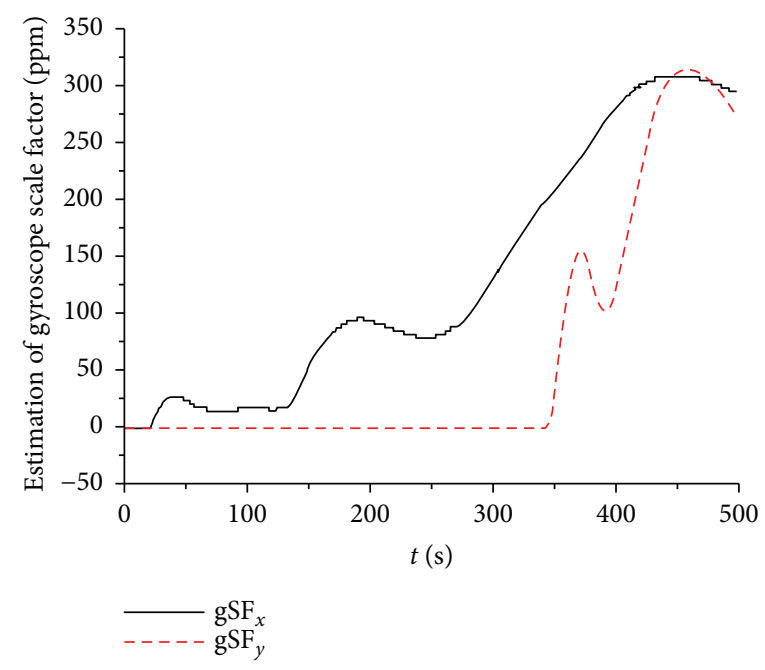

(b)

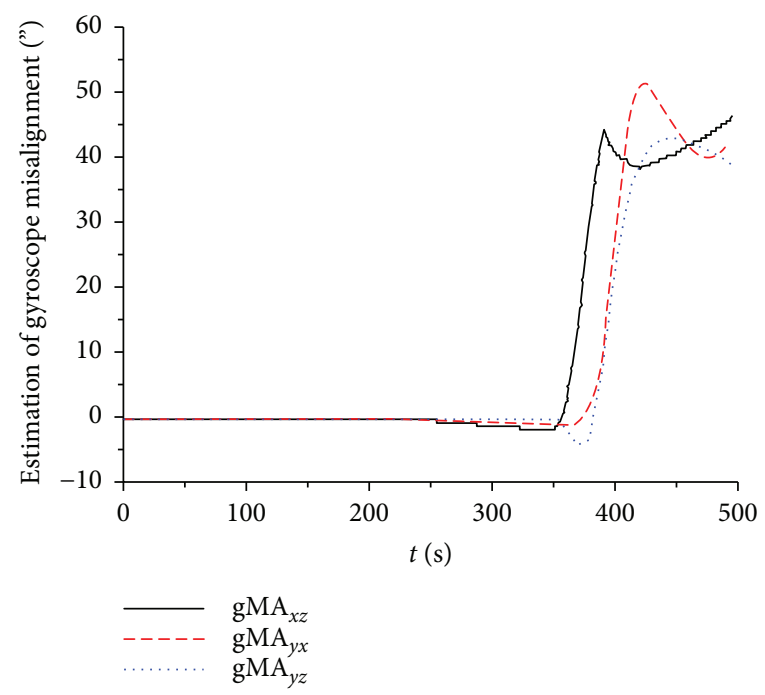

(c)

FIGURE 5: Estimation of gyroscope errors. (a) Estimation of gyroscope bias. (b) Estimation of gyroscope scale factor. (c) Estimation of gyroscope misalignment. 


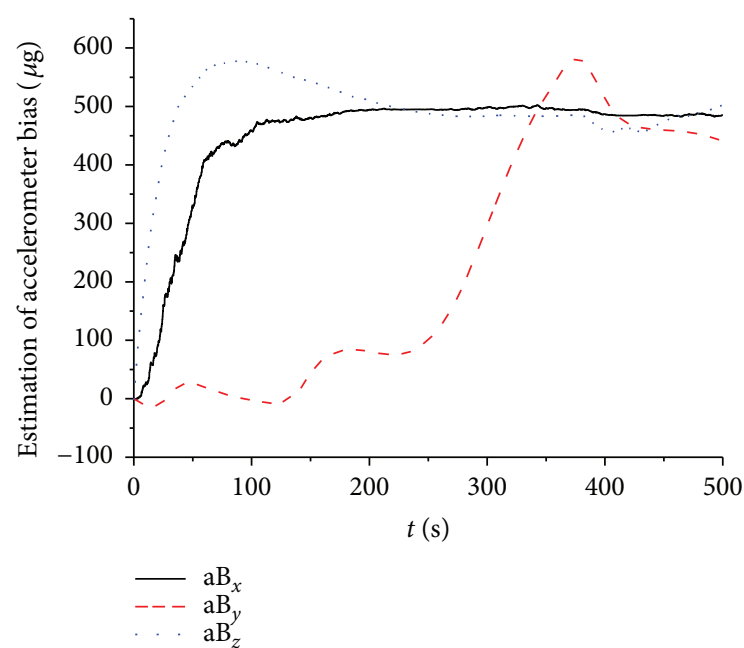

(a)

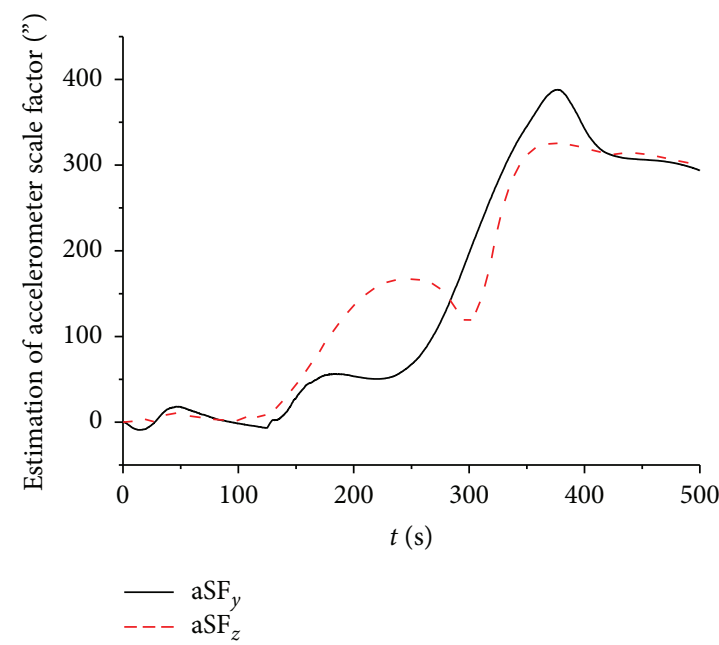

(b)

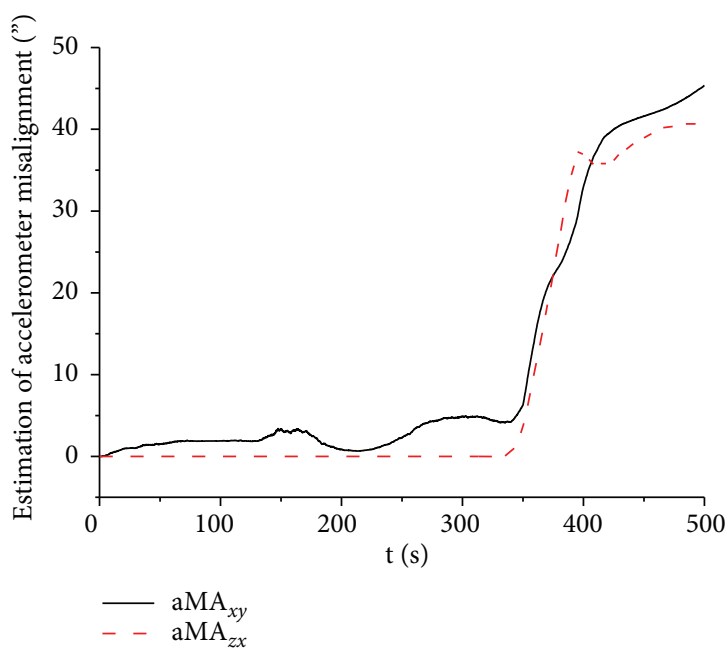

(c)

FIGURE 6: Estimation of accelerometer errors. (a) Estimation of accelerometer bias. (b) Estimation of accelerometer scale factor. (c) Estimation of accelerometer misalignment. computer. Turntable is one of the important equipment in test for simulating the change of attitude and attitude rate of aircraft in space. INS/GPS integrated navigation system consists of inertial navigation system and GPS receiver. The installation of the main test equipment is shown in Figures 8 and 9.

The error values of IMU are shown in Table 4.

Based on the analysis of the typical airborne trajectory, turntable is used to simulate the typical airborne movement. The rotation parameter of the turntable during the test is shown in Table 5.

The simulation time is 700 seconds, the first 500 seconds for INS/GPS integrated navigation. Integrated system turns into inertial navigation mode after 500 seconds. The test results are as follows, Figure 10 shows the estimation of gyroscope bias, scale factor error, and misalignment error in integrated navigation. Figure 11 shows the estimation of accelerometer bias, scale factor error, and misalignment error in integrated navigation. Figure 12 shows the estimation of position error of the traditional integrated navigation model and the proposed navigation model in the whole process, including the east position error, the north position error, and the upward position error.

From Figures 10-12, observable error estimation status of IMU in the integrated navigation process is shown in Table 6.

As can be seen from Table 6, there are 7 observable errors of IMU of which the estimation accuracy is more than $80 \%$. There are 4 observable errors of which the estimation accuracy is between $50 \%$ and $80 \%$, and there are 4 observable errors between $20 \%$ and $50 \%$. Consequently, most of the observable errors of IMU are effectively estimated in the integrated navigation process.

From the test results above, we can conclude that after 500 seconds integrated navigation and 200 seconds inertial navigation, the position errors of the east, north, and upward of the traditional model are $798.3 \mathrm{~m}, 550.6 \mathrm{~m}$, and $207 \mathrm{~m}$, respectively. The east, north, and upward position errors of the proposed integrated model are $592.2 \mathrm{~m}, 444.8 \mathrm{~m}$, and $176.6 \mathrm{~m}$, respectively. The navigation accuracy of the east, north, and upward positions of the proposed model improved by $25.8 \%, 19.2 \%$, and $14.7 \%$, respectively. Consequently, the integrated navigation method proposed in this paper can achieve higher navigation accuracy. So the integrated navigation model proposed in this paper is superior and effective.

\section{Conclusions}

The influence of scale factor error and misalignment error on navigation accuracy is analyzed in this paper. Based on the analysis, scale factor error and misalignment error are considered in the error state vector. Then the observability of scale factor error and misalignment error is analyzed combined with typical airborne movement. The integrated system is optimized according to the observability analysis results. Finally, this method is verified by numerical simulation and turntable test. The results all show that the INS/ GPS integrated navigation model proposed in this paper 


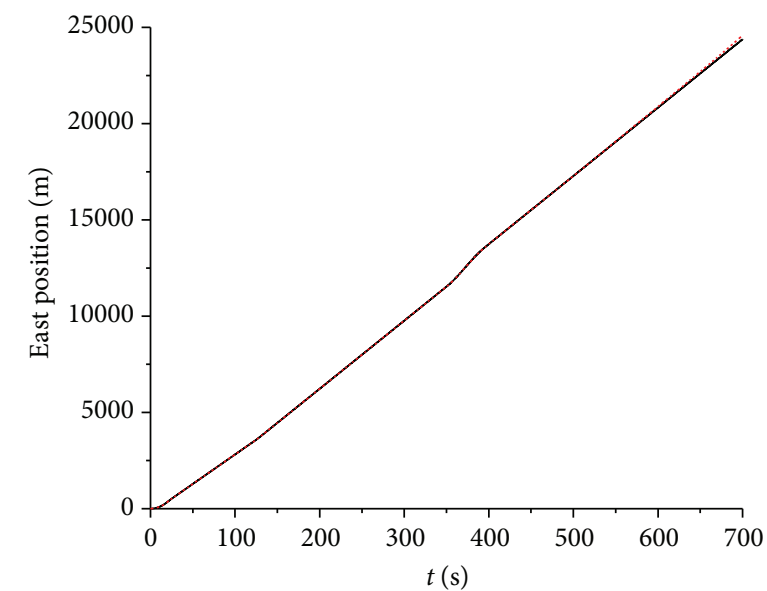

True value ....... Proposed integrated model

(a)

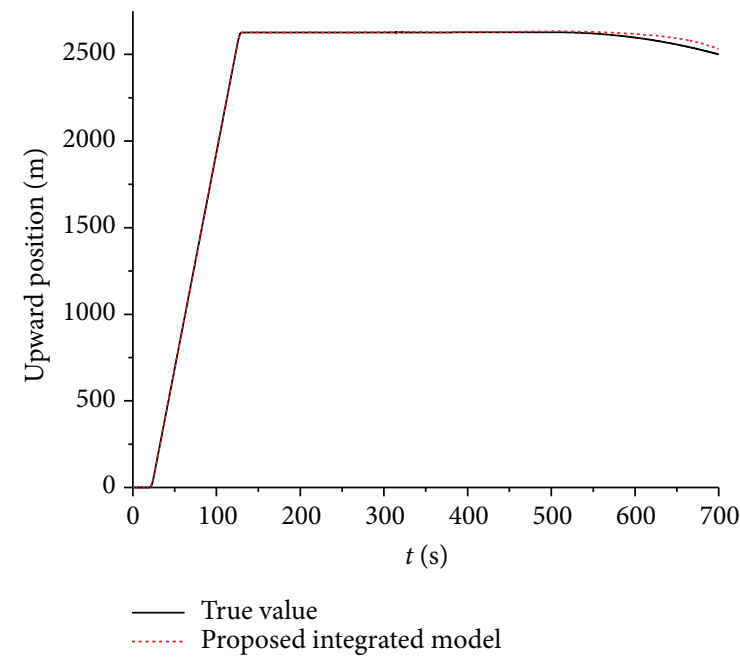

(c)

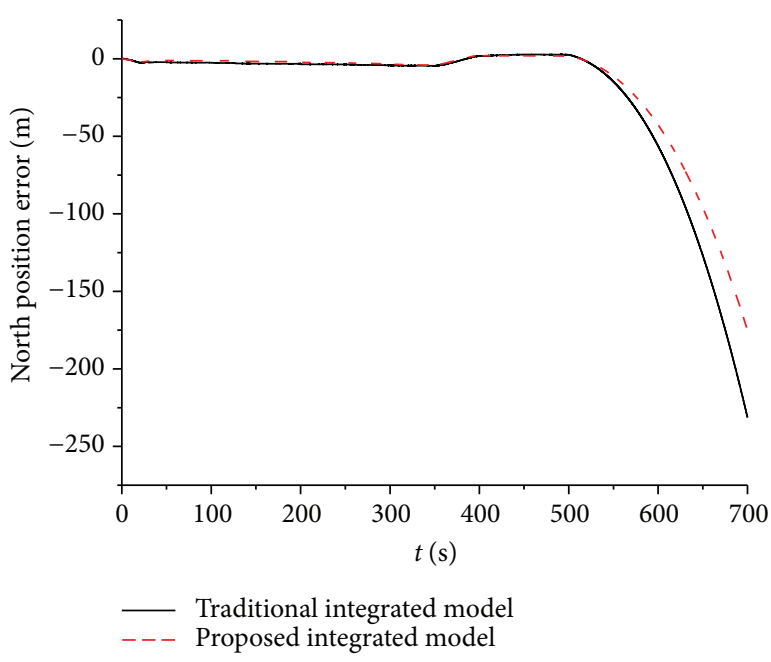

(e)

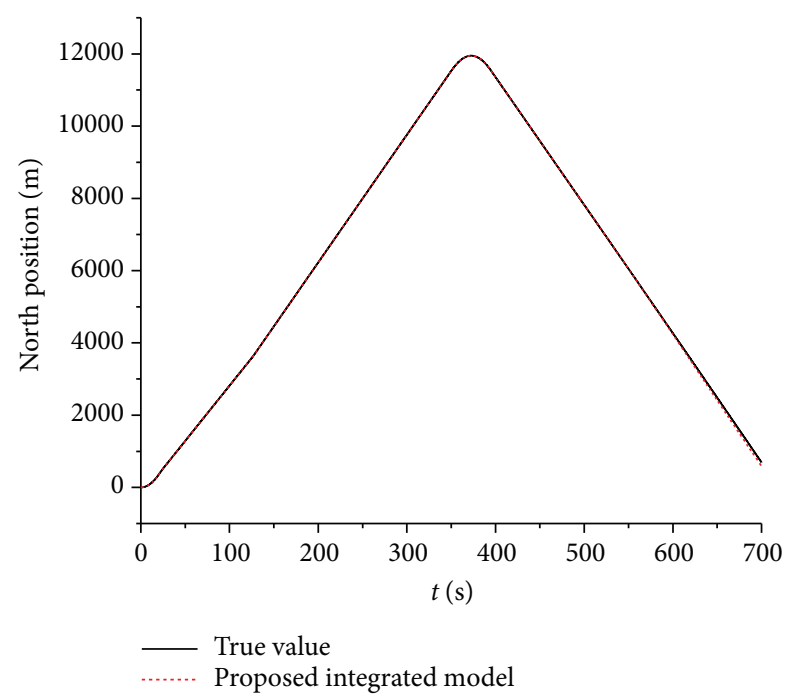

(b)

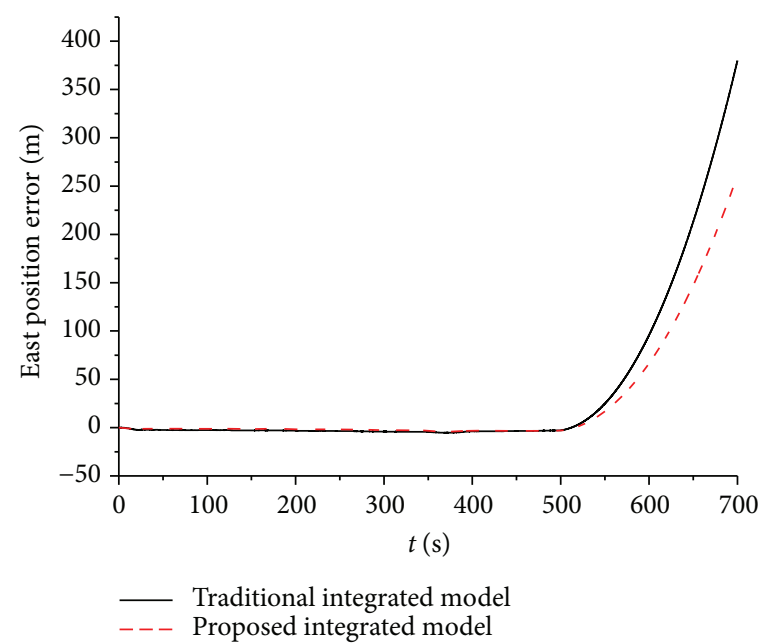

(d)

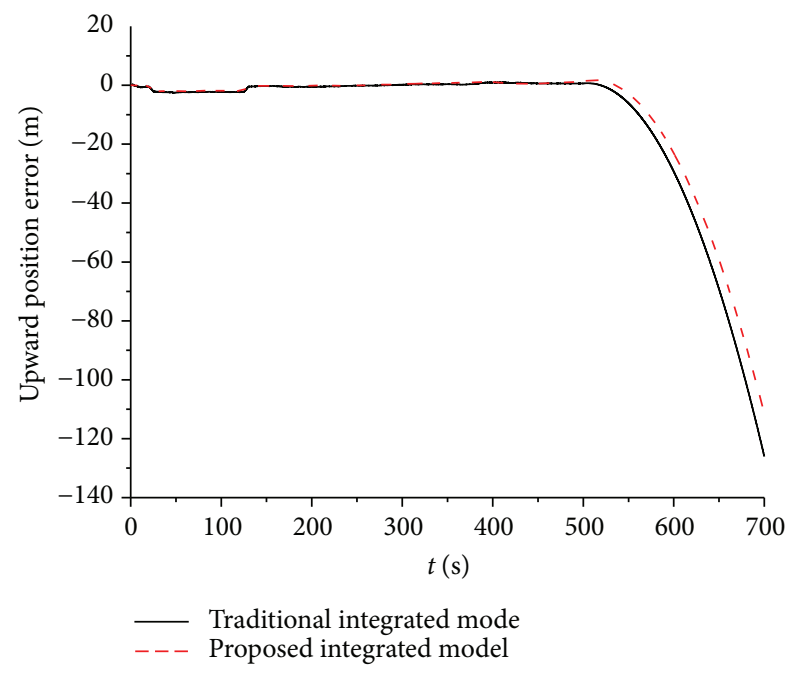

(f)

Figure 7: Estimation of position. (a) Calculation of east position. (b) Calculation of north position. (c) Calculation of upward position. (d) Estimation of east position error. (e) Estimation of north position error. (f) Estimation of upward position error. 


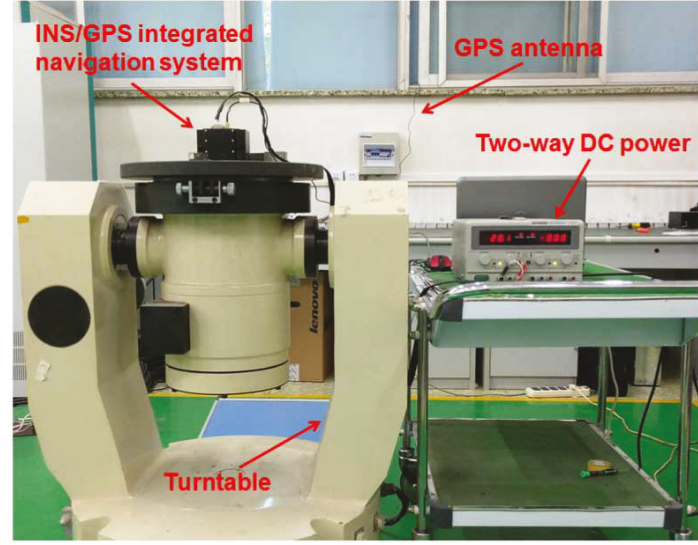

FIGURE 8: Installation of the test equipment.

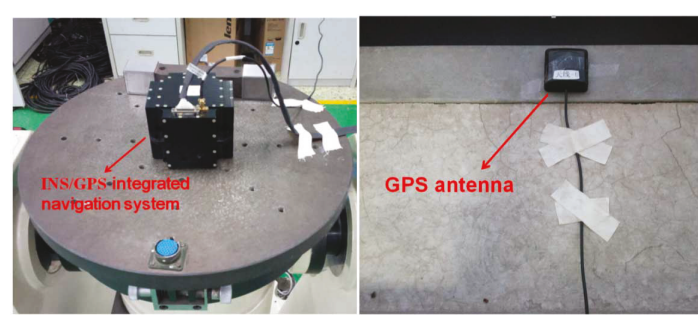

FIGURE 9: Installation of the integrated system and GPS antenna.

TABLE 4: Error values of IMU.

\begin{tabular}{lc}
\hline Gyroscope errors & \\
Bias & $1^{\circ} / \mathrm{h}$ \\
Scale factor & $300 \mathrm{ppm}$ \\
Misalignment & $40^{\prime \prime}$ \\
Accelerometer errors & \\
Bias & $500 \mu \mathrm{g}$ \\
Scale factor & $300 \mathrm{ppm}$ \\
Misalignment & $40^{\prime \prime}$ \\
\hline
\end{tabular}

TABLE 5: Rotation parameter setting of turntable.

\begin{tabular}{lcc}
\hline Time & Dynamic situation & Rate of rotation \\
\hline $0 \sim 20$ & Still & \\
$20 \sim 25$ & Pitch rotate $30^{\circ}$ & $6^{\circ} / \mathrm{s}$ \\
$25 \sim 125$ & Still & \\
$125 \sim 130$ & Pitch rotate $-30^{\circ}$ & $-6^{\circ} / \mathrm{s}$ \\
$130 \sim 330$ & Still & \\
$330 \sim 350$ & Roll rotate $20^{\circ}$ & $1^{\circ} / \mathrm{s}$ \\
$350 \sim 395$ & Yaw rotate $90^{\circ}$ & $2 \%$ \\
$395 \sim 415$ & Roll rotate $-20^{\circ}$ & $-1^{\circ} / \mathrm{s}$ \\
$415 \sim 700$ & Still & \\
\hline
\end{tabular}

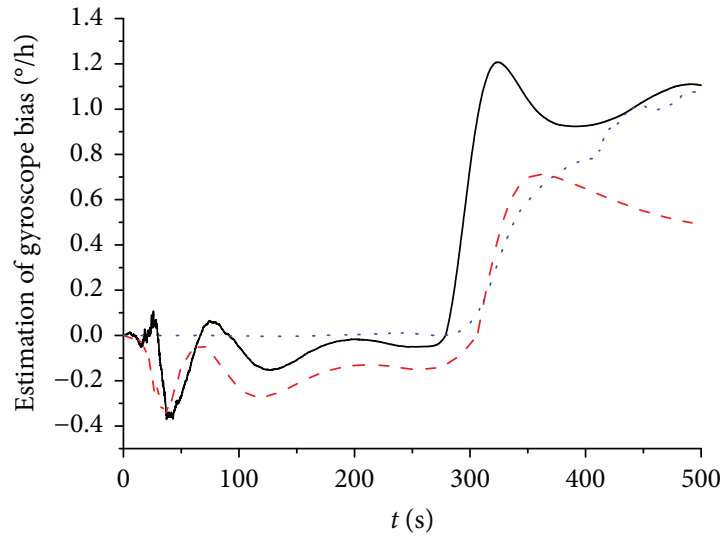

$-\mathrm{gB}_{x}$
$--\mathrm{gB}_{y}$
$\mathrm{gB}_{z}$

(a)

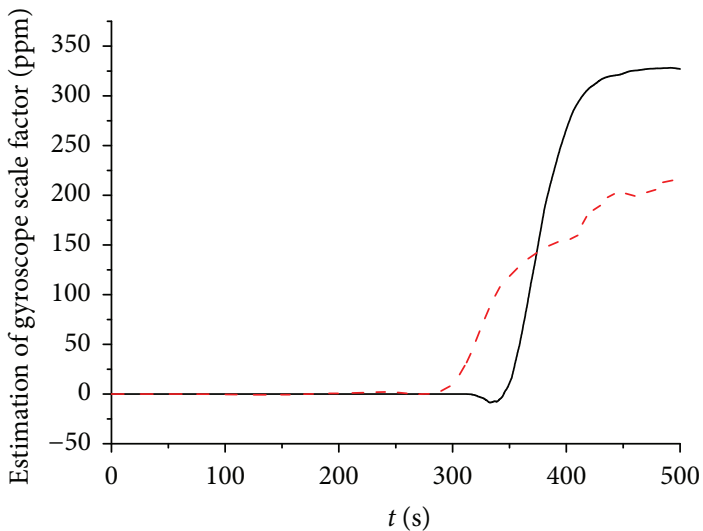

$-\operatorname{gSF}_{x}$

(b)

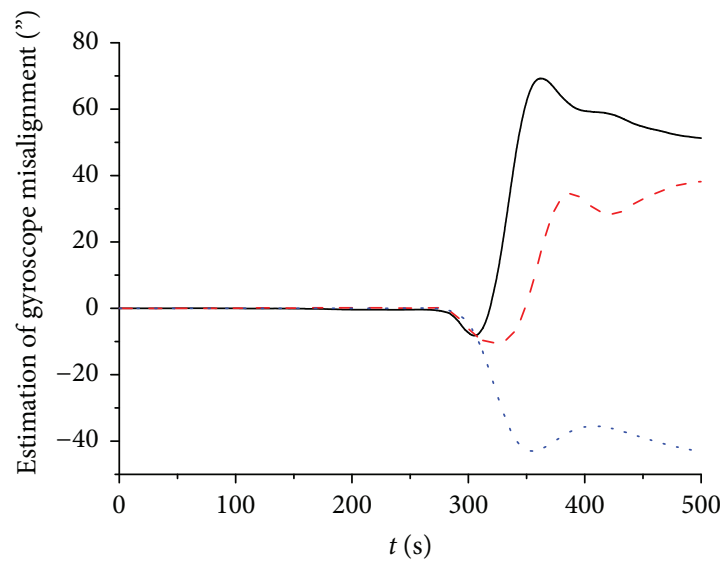

$-\underset{---}{\operatorname{gMAA}} x$

$\mathrm{gMA}_{y z}$

(c)

Figure 10: Estimation of gyroscope errors. (a) Estimation of gyroscope bias. (b) Estimation of gyroscope scale factor.

(c) Estimation of gyroscope misalignment. 


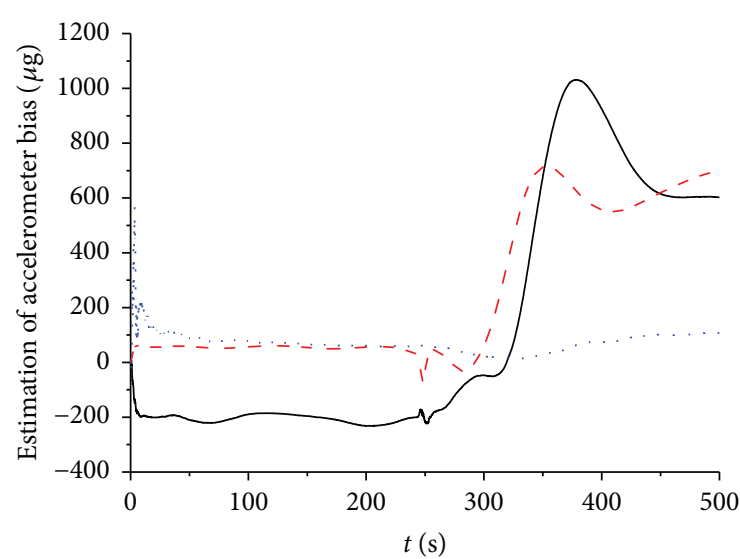

$\begin{array}{ll}-- & \mathrm{aB}_{x} \\ -\cdots & \mathrm{aB}_{y}\end{array}$

(a)

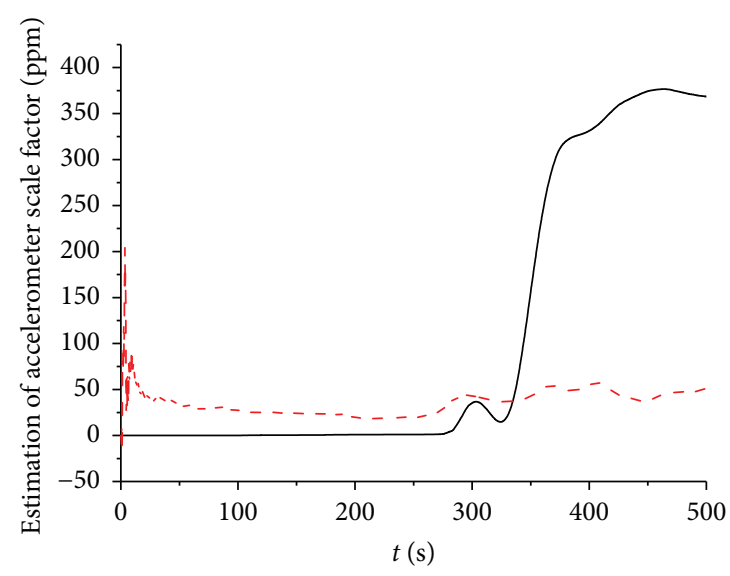

$-\operatorname{aSF}_{---} \operatorname{aSF}_{z}$

(b)

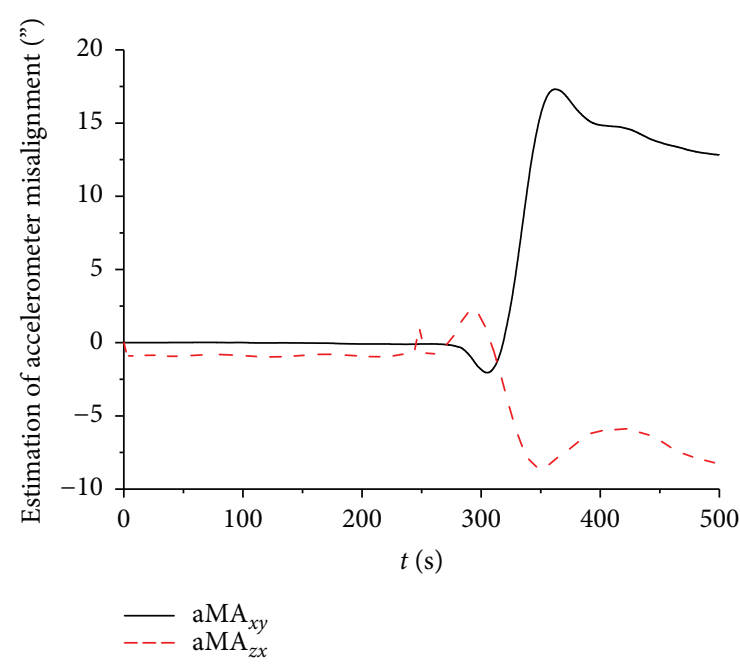

(c)

FIGURE 11: Estimation of accelerometer errors. (a) Estimation of accelerometer bias. (b) Estimation of accelerometer scale factor. (c) Estimation of accelerometer misalignment.

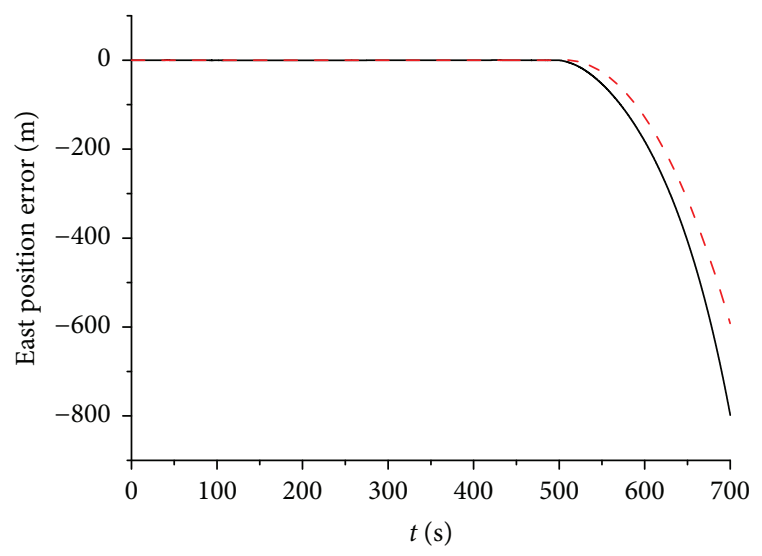

— Traditional integrated model Proposed integrated model

(a)

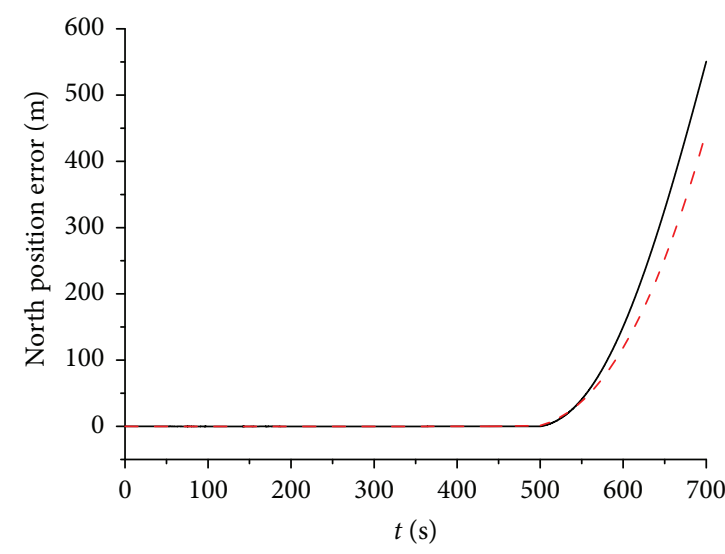

Traditional integrated mode - - - Proposed integrated model

(b)

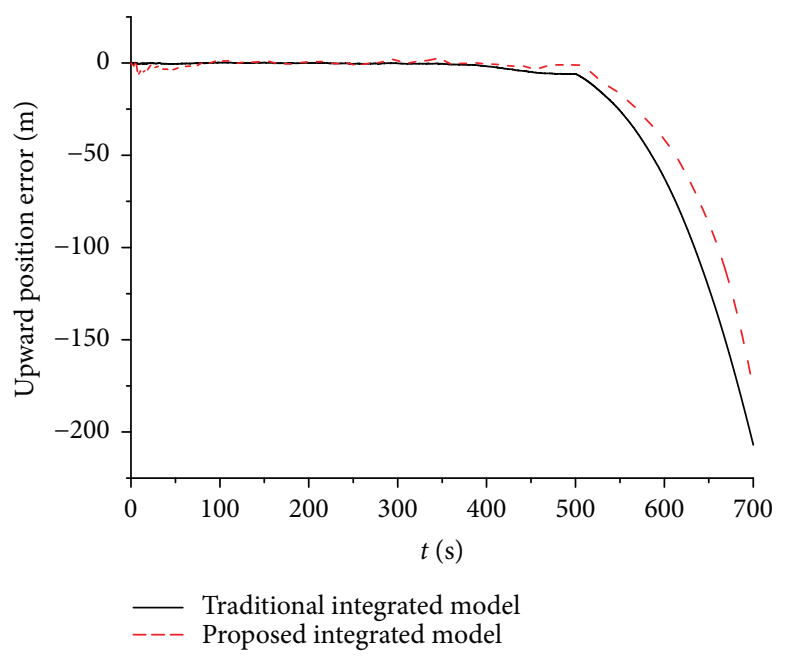

(c)

FIGURE 12: Estimation of position errors. (a) Estimation of the east position error. (b) Estimation of the north position error. (c) Estimation of the upward position error. 
TABLE 6: Observable error estimation status of IMU.

\begin{tabular}{lccc}
\hline Observable error & Test value & Estimated value & $\begin{array}{c}\text { Accuracy of } \\
\text { estimation }\end{array}$ \\
\hline $\mathrm{gB}_{x}$ & $1^{\circ} / \mathrm{h}$ & $1.1^{\circ} / \mathrm{h}$ & $91 \%$ \\
$\mathrm{gB}_{y}$ & $1^{\circ} / \mathrm{h}$ & $1.1^{\circ} / \mathrm{h}$ & $91 \%$ \\
$\mathrm{gB}_{z}$ & $1^{\circ} / \mathrm{h}$ & $0.5^{\circ} / \mathrm{h}$ & $50 \%$ \\
$\mathrm{gSF}_{x}$ & $300 \mathrm{ppm}$ & $327 \mathrm{ppm}$ & $90 \%$ \\
$\mathrm{gSF}_{y}$ & $300 \mathrm{ppm}$ & $214 \mathrm{ppm}$ & $71 \%$ \\
$\mathrm{gMA}_{x z}$ & $40^{\prime \prime}$ & $51^{\prime \prime}$ & $78 \%$ \\
$\mathrm{gMA}_{y x}$ & $40^{\prime \prime}$ & $38^{\prime \prime}$ & $95 \%$ \\
$\mathrm{gMA}_{y z}$ & $40^{\prime \prime}$ & $-43^{\prime \prime}$ & $93 \%$ \\
$\mathrm{aB}_{x}$ & $500 \mu \mathrm{g}$ & $602 \mu \mathrm{g}$ & $83 \%$ \\
$\mathrm{aB}_{y}$ & $500 \mu \mathrm{g}$ & $702 \mu \mathrm{g}$ & $71 \%$ \\
$\mathrm{aB}_{z}$ & $500 \mu \mathrm{g}$ & $107 \mu \mathrm{g}$ & $21 \%$ \\
$\mathrm{gSF}_{y}$ & $300 \mathrm{ppm}$ & $369 \mathrm{ppm}$ & $81 \%$ \\
$\mathrm{gSF}_{z}$ & $300 \mathrm{ppm}$ & $62 \mathrm{ppm}$ & $21 \%$ \\
$\mathrm{aMA}_{x y}$ & $40^{\prime \prime}$ & $13^{\prime \prime}$ & $33 \%$ \\
$\mathrm{aMA}_{z x}$ & $40^{\prime \prime}$ & $-8^{\prime \prime}$ & $20 \%$ \\
\hline & & &
\end{tabular}

can obtain more effective estimation of IMU errors than traditional integrated navigation model. In addition, when GPS becomes invalid, the proposed integrated model can achieve higher navigation accuracy.

\section{Conflicts of Interest}

The authors declare that there are no conflicts of interest regarding the publication of this paper.

\section{References}

[1] H. Han, J. Wang, and M. Du, "A fast SINS initial alignment method based on RTS forward and backward resolution," Journal of Sensors, vol. 2017, Article ID 7161858, 11 pages, 2017.

[2] X. Wang and W. Ni, "An improved particle filter and its application to an INS/GPS integrated navigation system in a serious noisy scenario," Measurement Science and Technology, vol. 27, no. 9, article 095005, 2016.

[3] G. Grunwald, M. Bakuła, A. Ciećko, and R. Kaźmierczak, "Examination of GPS/EGNOS integrity in north-eastern Poland," IET Radar, Sonar \& Navigation, vol. 10, no. 1, pp. 114-121, 2016.

[4] Y. Li, G. Sun, and W. Jiang, GPS/BeiDou/INS Performance in Two Hemispheres, Inside GNSS, NJ, USA, 2013.

[5] R. T. Kelley, N. A. Carlson, and S. Berning, "Integrated inertial network," in Proceedings of 1994 IEEE Position, Location and Navigation Symposium - PLANS'94, pp. 439-446, Las Vegas, NV, USA, April 1994.

[6] R. H. Liu and L. Z. Liang, "Status and prospect of INS/CNS/ GNSS integrated navigation technology," Modern Navigation, vol. 28 , no. 6 , pp. $62-65,2014$.
[7] H. J. Lei and Y. C. Zhang, Review of Airborne Inertial Navigation Technology, Xi'an Flight Automatic Control Research Institute, Xi'an, China, 2016.

[8] Y. Bai, Q. Sun, L. Du, M. Yu, and J. Bai, "Two laboratory methods for the calibration of GPS speed meters," Measurement Science and Technology, vol. 26, no. 1, article 015005, 2015.

[9] S. Han and J. Wang, "Land vehicle navigation with the integration of GPS and reduced INS: performance improvement with velocity aiding," The Journal of Navigation, vol. 63, no. 1, pp. 153-166, 2010.

[10] S. Han and J. Wang, "A novel initial alignment scheme for low-cost INS aided by GPS for land vehicle applications," The Journal of Navigation, vol. 63, no. 4, pp. 663-680, 2010.

[11] H. Peng, Z. Xiong, R. Wang, J. Liu, and J. Wang, "Dynamic parameter identification research on the installation errors and the scale factor errors of the IMU," Chinese Space Science and Technology, vol. 34, no. 1, pp. 42-49, 2014.

[12] G. Zhou, J. Wang, and K. Li, "Analysis of singular value under Kalman filtering for strapdown inertial system online calibration," in Lecture Notes in Electrical Engineering, pp. 779-784, Springer, Berlin, Heidelberg, 2011.

[13] Y. Y. Qin, Inertial Navigation, Science Press, Beijing, China, 2015.

[14] X. Zhang, H. Shi, and C. Zhang, "Integrated navigation method based on inertial navigation system and Lidar," Optical Engineering, vol. 55, no. 4, article 044102, 2016.

[15] X. L. Wang and Y. F. Li, SINS/GPS Integrated Navigation Technology, Beihang University Press, Beijing, China, 2014.

[16] H. N. Wang, Principles and Applications of GPS Navigation, Science Press, Beijing, China, 2003.

[17] Q. Wang, W. Gao, M. Diao, F. Yu, and Y. Li, "Coarse alignment of a shipborne strapdown inertial navigation system using star sensor," IET Science, Measurement \& Technology, vol. 9, pp. 852-820, 2016.

[18] W. Feng and J. Wang, "Design and implementation of flight track simulation system," Computer Simulation, vol. 12, pp. 47-50, 2010.

[19] F. Xu, J. C. Fang, and W. Quan, "Hardware in-the-loop simulation of SINS/CNS/GPS integrated navigation system," Journal of System Simulation, vol. 20, no. 2, pp. 332-385, 2008. 


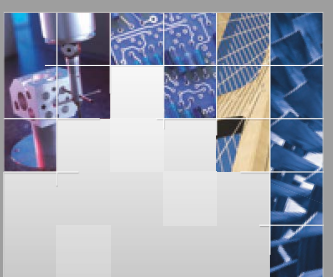

\section{Enfincering}
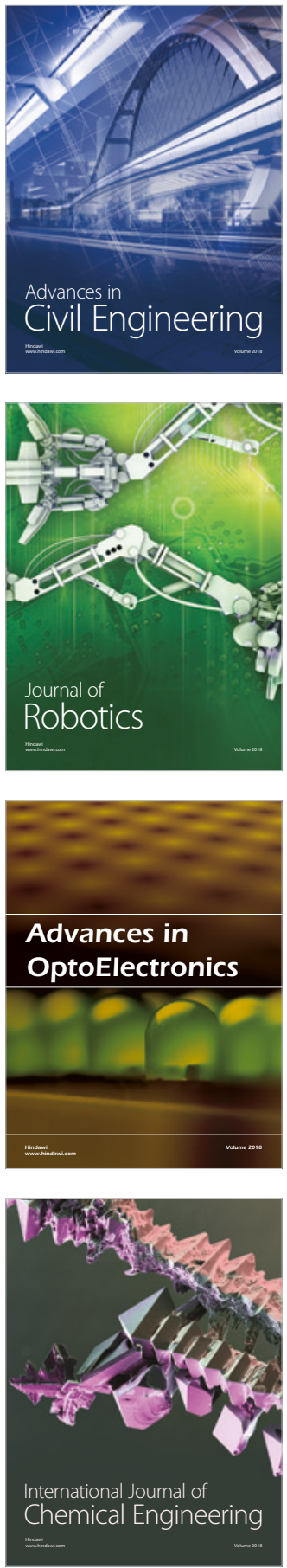

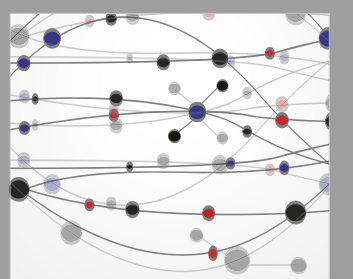

\section{Rotating \\ Machinery}

The Scientific World Journal

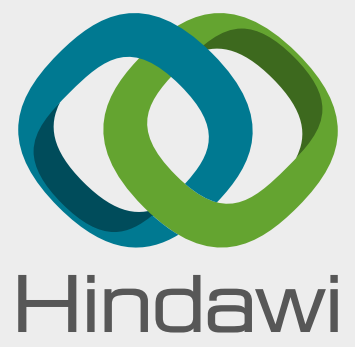

Submit your manuscripts at

www.hindawi.com
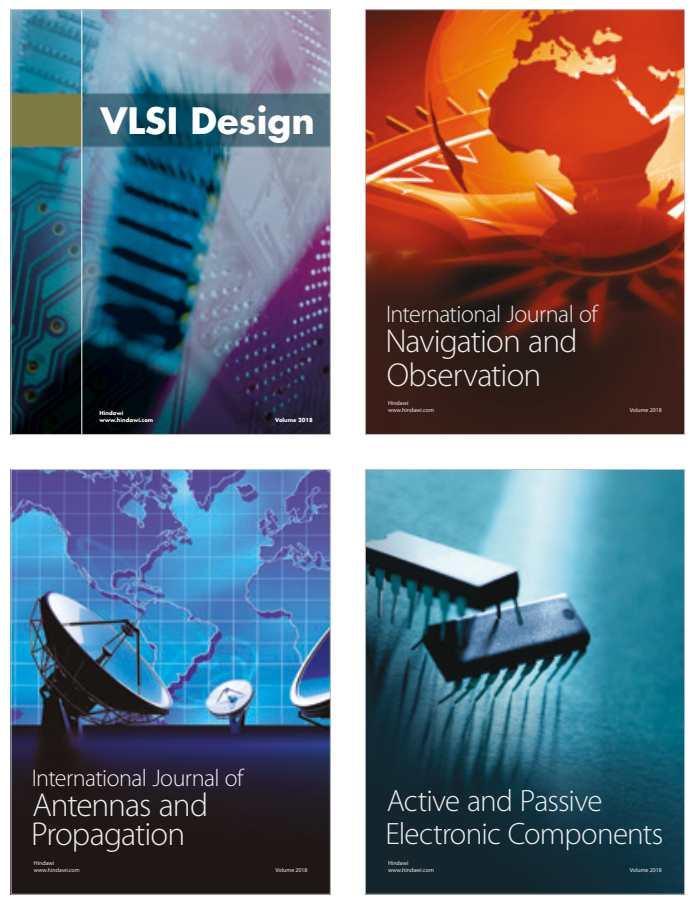
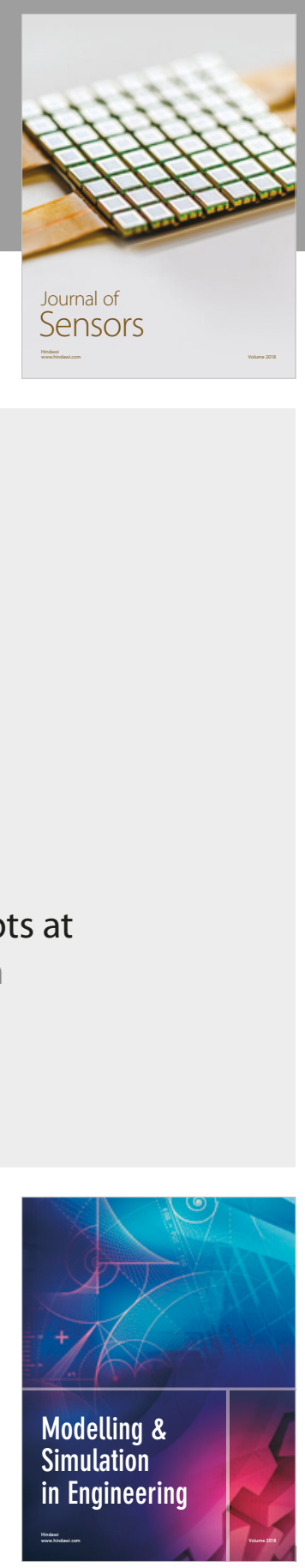

\section{Advances \\ Multimedia}
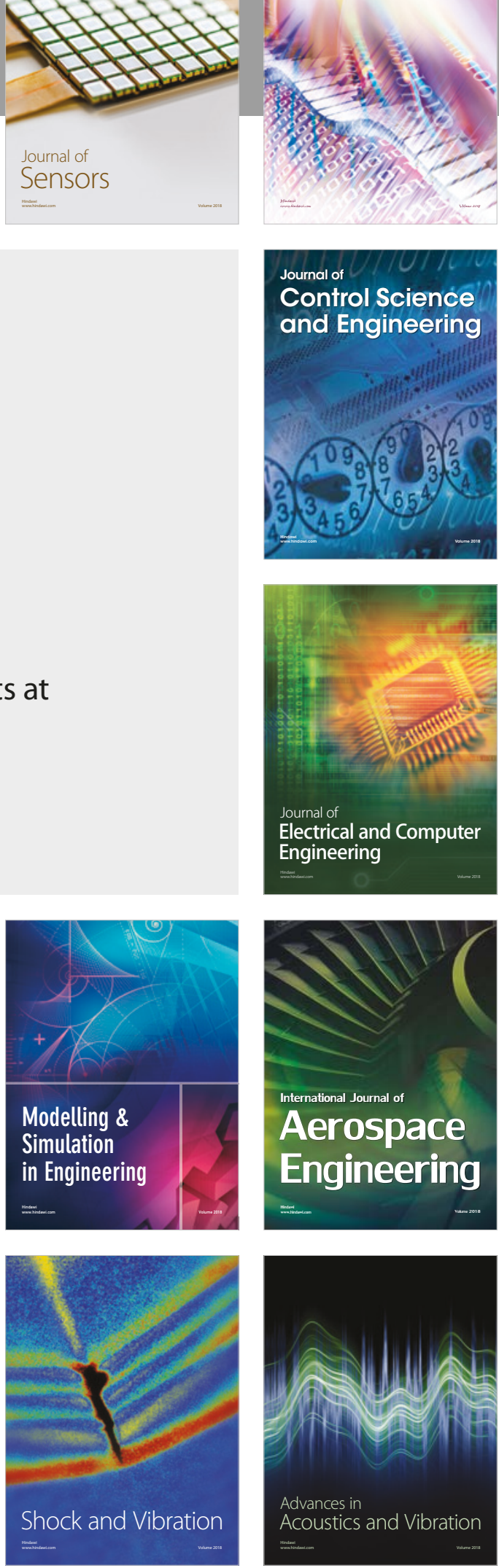